\title{
SOME INNOVATIVE SURFACE TEXTURING TECHNIQUES FOR TRIBOLOGICAL PURPOSES
}

\begin{tabular}{|c|c|}
\hline Journal: & Part J: Journal of Engineering Tribology \\
\hline Manuscript ID: & JET-13-0251.R1 \\
\hline Manuscript Type: & Special Issue \\
\hline Date Submitted by the Author: & $n / a$ \\
\hline Complete List of Authors: & $\begin{array}{l}\text { Costa, Henara; Universidade Federal de Uberlandia, School of Mechanical } \\
\text { Engineering } \\
\text { Hutchings, I; University of Cambridge }\end{array}$ \\
\hline Keywords: & $\begin{array}{l}\text { surface texturing, lubrication, photochemical texturing, electrochemical } \\
\text { texturing, inkjet printing }\end{array}$ \\
\hline Abstract: & $\begin{array}{l}\text { This paper reviews methods for texturing surfaces for tribological } \\
\text { applications, and presents some innovative methods that could make } \\
\text { surface texturing more cost-effective. Possible texturing methods were } \\
\text { identified and classified according to their physical principles. This involved } \\
\text { identifying existing texturing methods and also led to proposals for new } \\
\text { possible methods. Three innovative texturing methods with low cost and } \\
\text { high texturing speed are then presented: } i \text {. a simpler and cheaper version } \\
\text { of photochemical texturing; ii. maskless electrochemical texturing (MECT), } \\
\text { and iii. masking surfaces by inkjet printing followed by etching. From } \\
\text { these, MECT was the cheapest and fastest, but the minimum size of the } \\
\text { texture features was the largest. Inkjet printing followed by etching is as } \\
\text { an alternative that may potentially provide a good combination of cost and } \\
\text { resolution, but the texturing time depends on the surface area. Then, an } \\
\text { attempt was made to delimit tribological applications where the use of such } \\
\text { processes could be beneficial, based on analysis of experimental results of } \\
\text { their tribological evaluation. These showed that the methods proposed } \\
\text { could be particularly suited for components with contact areas larger than } \\
\text { the width of the texture features under either hydrodynamic lubrication or } \\
\text { starved lubrication. }\end{array}$ \\
\hline
\end{tabular}

\section{SCHOLARONE ${ }^{\text {M }}$ \\ Manuscripts}




\section{$\begin{array}{llllll}\text { SOME INNOVATIVE } & \text { SURFACE } & \text { TEXTURING } & \text { TECHNIQUES } & \text { FOR }\end{array}$ TRIBOLOGICAL PURPOSES} Costa, H.L. ${ }^{1}$ and Hutchings, I.M. ${ }^{2}$

1. Universidade Federal de Uberlândia, School of Mechanical Engineering, Laboratory of Tribology and Materials, Campus Santa Mônica, Sala 1M220, Uberlândia, MG, 38400901, Brazil,e-mail: ltm-henara@ufu.br,phone: +55 3432394036.

${ }^{2}$ University of Cambridge, Institute for Manufacturing, Dept. of Engineering, 17 Charles Babbage Road, Cambridge,CB3 OFS, UK, e-mail: imh2@,cam.ac.uk, phone: +441223765217 .

Abstract. This paper reviews methods for texturing surfaces for tribological applications, and presents some innovative methods that could make surface texturing more cost-effective. Possible texturing methods were identified and classified according to their physical principles. This involved identifying existing texturing methods and also led to proposals for new possible methods. Three innovative texturing methods with low cost and high texturing speed are then presented: $i$. a simpler and cheaper version of photochemical texturing; $i$. maskless electrochemical texturing (MECT), and iii. masking surfaces by inkjet printing followed by etching. From these, MECT was the cheapest and fastest, but the minimum size of the texture features was the largest. Inkjet printing followed by etching is as an alternative that may potentially provide a good 
combination of cost and resolution, but the texturing time depends on the surface area. Then, an attempt was made to delimit tribological applications where the use of such processes could be beneficial, based on analysis of experimental results of their tribological evaluation. These showed that the methods proposed could be particularly suited for components with contact areas larger than the width of the texture features under either hydrodynamic lubrication or starved lubrication.

Keywords: Surface texturing, inkjet printing, electrochemical texturing, photochemical texturing hydrodynamic lubrication, starvation.

\author{
Nomenclature \\ $a$ - distance from the inlet to the first pocket \\ $B$ - pocket width \\ $C W$ - contact width \\ $d$ - pocket diameter \\ $f$ - fraction of area coverage \\ $h$ - depth of the features \\ $l$ - length of the arms of the chevrons \\ $p_{x}$ - distance between features in the $x$ direction \\ $p_{y}$ - distance between features in the $y$ direction \\ $t_{o}$ - duration of intervals between working pulses \\ $t_{p}-$ duration of working pulses
}


$w$ - width of the lines

$w_{c}$ - width of the arms of the chevrons

$T S$ - non-dimensional parameter associated to the width of the pockets

\section{Greek symbols}

$\beta$-included angle of the chevrons

\section{Abbreviations}

3D - three-dimension

CFD - computational fluid dynamics

$\mathrm{CNC}$ - computer numerical control

CVD - chemical vapour deposition

EBT - electron beam texturing

ECP - electrochemical printing

EDM - electro discharge machining

EDT - electro discharge texturing

EHL - elastohydrodynamic lubrication

FEM - finite element modelling

FIB - focused ion beam

HAB - hot air blower 
IBT - ion beam texturing

IMS $=$ industrial methylated spirit

LT - laser texturing

MECT - maskless electrochemical texturing

PCT - Photochemical texturing

SEM - scanning electron microscopy

USC - ultrasonic cleaning

$\mathrm{UV}$ - ultra violet

\section{Introduction}

Surface texturing consists of modifying surface topography in order to create a uniform microrelief composed of regularly distributed asperities or depressions with controlled geometry. Surface texturing has been used for many different purposes [1], including improvement of tribological performance. The mechanisms responsible for improving the tribological performance of textured surfaces can vary significantly between applications and positive results have been shown for situations varying from dry sliding [2], to solid lubrication [3], hydrodynamic lubrication [4-10], elastohydrodynamic lubrication (EHL) $[11,12]$ and mixed lubrication $[13,14]$. In addition, surface texturing can help to entrap wear debris [15]. However, the successful use of surface texturing in tribological applications still faces two main challenges: $i$. 
careful design of the texture patterns is necessary for surface texturing to be beneficial, and ii: cost-effective surface texturing methods need to be designed for situations involving large volume production of cheap components.

One of the most successful tribological applications of surface texturing is the increase of load bearing capacity of moving surfaces under hydrodynamic lubrication. Considerable effort in the last two decades has tried to optimize the increase of load bearing capacity and the reduction of friction in hydrodynamic lubrication as a function of either texture parameters, such as shape, size and distribution of the features that compose the pattern, or operational parameters, such as load and speed [5-7]. Particular emphasis should be given to the extensive work carried out by Etsion and collaborators. They have developed analytical models to solve the Reynolds equation for textured surfaces for different engineering applications and a good review of their work can be found in [8]. More recently, other researchers have suggested that the use of massconserving algorithms to solve the Reynolds equation numerically might be more adequate for cavitated films $[16,17]$, since the occurrence of cavitation is responsible for the asymmetrical pressure distribution over individual pockets and therefore a net load support for textured surfaces. Fowell et al. [16] argue that mass-conserving algorithms can provide more realistic accounts of the benefits achievable when texturing hydrodynamic bearings. Another, different approach has used CFD simulations, based on the numerical solution of the Navier-Stokes and energy equations 
for incompressible flows [9]. Experimental work has also showed the benefits of surface texturing under hydrodynamic lubrication $[4,8,10,18]$. Some common points emerge from the works cited above, independently of whether they use theoretical or experimental approaches. In particular: $i$, preferably, the contact should be only partially textured, which limits the width of the individual features, so that in general positive results have been shown mostly for feature widths within the range of 10-100 $\mu \mathrm{m}$; $i$, the ratio between the depth and the width of the features should be small, generally in the range from 0.05 to 0.15 . This limits the depth of the features, so that normally, good results have been reported for feature depths in the range from around 1 to $15 \mu \mathrm{m}$.

The case of EHL is more challenging, but some researchers have also shown good results if the width of the micro features is substantially smaller than the contact width. Observation of the contact area by optical interferometry has shown that the lubricant expelled from the micro features can help to separate rubbing surfaces, especially under thin film lubrication conditions [11]. Experimental and numerical investigation of one individual micro feature (a circular dimple) inside an EHL contact under rolling-sliding conditions showed that deep dimples induced failure of the oil film, but shallow dimples generated a large increase in film thickness [12]. These authors believe that shallow features maintain the viscosity of the lubricant inside them high enough so that shearing can expel it to locally enhance film thickness. Due to the small size of EHL contacts, the 
width of the micro features that compose the texture generally becomes limited to values below $100 \mu \mathrm{m}$, and, according to the results of Mourier et al. [12], the depth should be preferably below $1 \mu \mathrm{m}$.

All the results described above for the effects of surface texturing on lubrication were obtained for contacts fully immersed in lubricant, i.e. there is always enough lubricant to fill the contact inlet. However, if lubricant starvation occurs in the contact, the film thickness will also depend on the amount of lubricant available in the contact [19]. Although lubricant side flow reduces film thickness in a starved contact when compared with an immersed contact, this lubricant may flow back to the contact inlet in the process known as lubricant replenishment $[20,21]$. In such situations, the texture features can be expected to act as lubricant micro-reservoirs that help to replenish the contact inlet, but it seems that no theoretical modeling yet exists to investigate this effect. The effect of surface texturing on friction under starved lubrication was investigated for polyoxymethylene [22], and it was observed that for very large aspect ratio between the depth and width of the micro features the lubricant "disappeared" from the contact and no friction reduction was detected. A similar lack of benefit from textured surfaces was found in [18] when very deep features were used under starved lubrication conditions.

The most successful method used today to texture surfaces in engineering applications is laser texturing [8]. It has been used to texture a wide range of materials, 
from polymers [23] to metals $[8,24]$ and ceramics $[15,25]$. Also, it allows the production of patterns with small features. For examples, feature depths of $200 \mathrm{~nm}$ and diameters of $20 \mu \mathrm{m}$ could be obtained in steel samples by using a femtosecond pulse laser [12]. The use of more sophisticated optics can lead to beam sizes below $5 \mu \mathrm{m}$. Another approach, based on laser-induced periodic surface structuring, used a femtosecond laser to produce an array of dimples with diameters of $1 \mu \mathrm{m}$, although the array of the dimples was not deterministic [26]. However, the use of laser texturing presents limitations. First, the ablation mechanism often leads to the formation of raised features around the pockets, which originate from the ejected molten material. These lateral rims are normally hard due to the microstructural changes caused by the process and can cause severe abrasive wear of the countersurface. After texturing, they therefore need to be removed, either by mechanical polishing, or by laser polishing [27, 28]. This phenomenon is practically eliminated when very short pulses (e.g. from femtosecond lasers) are used.

The second issue for laser texturing is the texturing speed. The process involves ablation, which changes the material state directly from solid to vapour in very short period of time, with little metallurgical surface damage. The ablation fluence threshold for materials varying from soft metals to glasses and hard composites stays in the range from 0.2 to $20 \mathrm{~J} \mathrm{~cm}^{-2}$ [29]. If the laser system has a sufficiently high maximum pulse energy, a micro dimple can be produced through laser ablation using a stationary laser 
spot with a size comparable to the dimple, and without the need for laser spot scanning, as long as the laser fluence (pulse energy/laser spot area) can at least exceed the ablation threshold fluence for the target material [28], and then the depth of the dimple will depend on the number of pulses. The use of high pulse energies, small spot diameters and (ultra)short pulse durations has allowed material removal by ablation to be achieved for a wide range of materials at increasing texturing speeds. However, since the features are normally produced in a serial sequence, the texturing time for larger components can still be long, in particular for cheaper laser texturing facilities, that use long pulse durations and large spot sizes. Many components that could have their performance increased by surface texturing are normally cheap, so they might require cheaper texturing methods in order for the increase in tribological performance achieved through texturing to be cost-effective. An alternative laser texturing technique that is substantially faster is laser interference texturing [30]. In this technique, interference fields produced by several coherent high power laser beams can produce periodic patterns composed of line-nets or dot-like features. The interference pattern covers a size corresponding to the beam diameter, which increases texturing speed substantially, but the maximum sizes of the individual features can be too small for some lubricated tribological applications (up to around $3 \mu \mathrm{m}$ in width and $1 \mu \mathrm{m}$ in depth). Therefore, such features might be desirable for applications involving EHL, but too small for hydrodynamic lubrication or starved lubrication. Another possible problem is that the 
process changes the topography of the whole surface, instead of only creating localized ablated features.

Other texturing methods have also been reported in the literature. Major advances in microfabrication have driven the area of surface texturing. In principle, many of the methods used in the microelectronics industry might be adapted to surface texturing. This paper reviews innovative texturing methods proposed and investigated by the present authors in recent years.

The aim was to explore some innovative surface texturing methods, to allow the benefits of surface texturing to be better explored in a wider range of practical applications, and to discuss their applicability to improve tribological performance. The next section presents a survey of possible texturing methods, classified according to the physical processes by which a surface texture could be produced. Conventional manufacturing methods that employ these physical principles have been studied. In addition, some new possible texturing methods that fall within the same groups have been proposed. After listing all possible texturing methods, an attempt is made to classify and compare them. Three methods that emerged from this comparison have been explored experimentally and their advantages and limitations are summarized. The criteria involved in selecting these methods were one or more of the following: simplicity of the technique, low cost, high texturing speed, and flexibility in terms of pattern geometry. Finally, the paper attempts to delimit tribological applications where 
their use could be beneficial, by examining experimental results from their tribological evaluation.

\section{Survey of possible surface texturing methods}

Alternative manufacturing technologies for surface texturing are needed to overcome the challenges of volume production. The technologies should be cheap and flexible, both in terms of the shapes of the features to be produced and the shapes of the surfaces to be textured. This section identifies most of the existing texturing methods and also proposes some new possible methods. However, the review is non-exhaustive because surface texturing has been extensively studied in recent years and new techniques appear very quickly. The methods have been categorized into four main groups according to their physical principles:

Adding material: the pattern features are created by addition of material to the desired surface, creating small areas of relief [31-47].

Removing material: the features are created by removal of material of the surface, creating small depressions $[4,8,12,15,23-25,48-75]$.

Moving material: the change in the surface structure is attributable to plastic deformation and redistribution of material from some parts of the surface to others [14, $30,48,76-81]$ 
Self-forming: wear-resistant regions are formed on a surface, so that a texture develops through wear of the surface, with the wear-resistant regions being left standing above the surrounding material [82-85].

Tree structures for each family with their taxonomy are presented in Figure 1 and references are presented for individual processes if possible. All the processes marked by '*' are processes that require a masking step before the texturing step. In Figure 2, methods that could be used to mask the surfaces are organized in a tree structure [8695].

In view of the wide variety of possible methods available for texturing surfaces, the choice for a specific method becomes difficult. Normally, the selection procedure is task-based and starts with the definition of requirements of a certain application. Most of the texturing methods screened are new and not yet well studied, which complicates the selection further. In order to assist this task, a database of texturing methods was created using CES Constructor (Granta Materials) of which details can be found in [96].

This comparison suggested that the choice of a texturing method is mainly based in the following criteria: simplicity of the texturing technique, commercial availability, equipment cost, texturing cost, texturing speed, minimum size of the individual features that compose the texture pattern, minimum and maximum depth of the features, and limitations in terms of the substrates to be textured: material, shape and size. 
Three alternative surface texturing techniques emerged as potential techniques to be used in some tribological applications, and were experimentally implemented. The first technique, called photochemical texturing, has been widely used and described in the literature, but this work presents some alternatives that reduce equipment and texturing cost. It is a very versatile technique in terms of shapes and patterns of the textures. The second method, called maskless electrochemical texturing (MECT), is potentially rapid and cheap, but the size and shape of the individual features produced is more limited. The third process involves masking the surface by inkjet printing, followed by chemical etching.

\section{Investigation of innovative surface texturing methods}

The main characteristics of the three alternative texturing techniques that were experimentally investigated will be described, trying to identify their current limitations, particularly in terms of the dimensions of the features that compose the texture. Then, in section 4 , the tribological performance of surfaces textured using such methods will be discussed, correlating this performance with the minimum dimensions achievable by each technique.

\section{Photochemical texturing (PCT)}

This texturing method consists of masking a steel surface by photolithography, followed by chemical etching. It has been used to texture steel surfaces to improve their 
performance in lubricated contacts [56, 57, 97], but the approach used here is significantly simplified when compared with conventional photolithography. A normal laboratory bench is used, which greatly reduces the complexity and costs of the process in comparison to use of a clean room. In order to extend this technique to an industrial environment, a clean workspace environment with controlled yellow illumination would be needed, since the photo-resist resin is not sensitive to light of this wavelength.

A sample spinner with maximum rotational speed of $7000 \mathrm{rpm}$ was used to ensure the formation of a thin and even resist layer on the steel plate surface. A conventional hot plate was used to bake the samples. A tungsten filament microscope light was used as a source of UV light to expose the resist. Various experimental conditions were tried, based on recommendations found in the literature [98].

Before texturing, the samples were cleaned in acetone in an ultrasonic bath. The photoresist (AZ 5214, manufactured by AZ Electronic Materials) was spun on to the surface. The coated sample was then pre-baked. The patterns were designed using Adobe Photoshop software and printed on to A4 paper using a laser printer. They were then photographed to make the masks to be used during the exposure of the resist. This reduced the cost and time that would be involved in the production of conventional metallic masks. However, the maximum area that could be textured was 35 x $35 \mathrm{~mm}$, which corresponds to the size of the photographic films. Another route which could probably give adequate resolution would be to print the pattern at the right size directly 
on to transparent film, by laser or inkjet methods. This would avoid the photographic step and would also increase the size of the area to be textured. However, it would also require a more powerful UV source covering a larger area. There would be challenges in treating components with large areas, above around $250 \times 250 \mathrm{~mm}$, with a single exposure using this technique.

The exposure to UV light was made by contact printing. After exposure, the samples were developed in AZ 351B developing solution and then post-baked to guarantee complete development of the resist. A $10 \%$ aqueous nitric acid solution was used to etch the steel samples at room temperature. The depth of the features was varied by changing the etching time. After etching, the resist was stripped in acetone at room temperature.

Photolithographic resists may be negative or positive. In positive resists, photochemical reactions caused by UV exposure weaken the polymer by scission of the main and side polymer chains. Thus, the exposed areas will be more soluble in developing solutions. Negative resists are strengthened by UV exposure, which promotes random cross-linking of the main or side of the resist. The exposed areas of the resist will be then less soluble in developing solutions. In this work, the use of different UV light sources allowed the same resin to be used as both a negative photoresist (using a lower power light source) and a positive photoresist (using a higher power light source). The conditions used for both conditions varied slightly, as summarized in Table I. 
This technique is very versatile in terms of the shapes of the features, which depends on the pattern printed on the masks. The resolution of this simplified procedure is worse than that obtained with conventional photolithography, but obviously depends on the resolution of the mask. For the conditions used in this work, the smallest features that could be produced with good repeatability were circular pockets with an average diameter of $20 \pm 1 \mu \mathrm{m}$.

In Figure 3, examples of the textures generated with the positive resist (pockets) and the negative resist (pillars) are shown. This technique was also used to produce linear and chevron-like grooves, as described in [4].

\section{Maskless electrochemical texturing (MECT)}

This is a simple method for texturing metallic surfaces by electrochemical machining, termed 'maskless electrochemical texturing' (MECT). It allows a single cathode tool, in which the texture is incorporated through a pattern of perforations, to be used for many texturing operations and avoids the need for masks to be applied to individual workpieces. It therefore has significant advantages over conventional methods of texturing by electrochemical machining that involve prior masking $[58,99]$. Locating the electrical insulation that localizes the machining action at the surface of the cathodic tool, instead of applying a mask to each individual workpiece, has been used previously by other authors. Schönenberger and Roy [59] transferred features in the size range from 50 to $200 \mu \mathrm{m}$ from a patterned cathode tool onto a copper workpiece. 
However, the approach in the present work is different, because the electrolyte flows through small perforations on the textured tool which define the pattern to be transferred, ensuring effective cleaning of the tool during machining. The quantity of electrolyte used to machine each workpiece is quite small and the whole apparatus is relatively simple. Finally, it is well suited for the treatment of quite large areas (typically $\mathrm{cm}^{2}$ to $\mathrm{dm}^{2}$ ). Nelson and Schwartz [33] have developed a process called electrochemical printing (ECP), which has some similarities but electrolytically deposits material rather than removing it. Furthermore, the process occurs at a single location rather than over a large number of areas in parallel. Another different configuration has also been used to texture steel surfaces using electrochemical machining without previous masking, but each pocket is produced individually, which substantially increases the texturing time [60].

During texturing, the potential difference between anode and cathode is switched, and consists of brief working pulses $\left(t_{p}\right)$, where anodic dissolution of the workpiece occurs, separated by intervals of duration $t_{o}$, where the electrolytic cell is at rest, and the products of anodic dissolution are flushed away from the inter-electrode gap.

Textured carbon steel samples could be produced using this technique with high current efficiencies as described elsewhere [71], and the process was characterized in terms of the effects of current pulse history and electrolyte flushing conditions on current efficiency, material removal rate and feature definition. The variables were the 
machining time, the pulse length, the pressure of the electrolyte and the separation between the polymer mask plate and the workpiece, obtained by the use of spacers with different thicknesses. Due to its simplicity and low cost, the technique has been investigated by other authors, who used FEM to model the technique [72].

Subsequently, micro EDM was used to texture the covers of the tools used for MECT, which enabled more complex features to be produced [100]. Also, the technique was optimized in terms of voltage applied between tool and specimen. AISI 420 stainless steel tool covers $0.5 \mathrm{~mm}$ in thickness were machined by die sinking EDM.

Patterns containing regularly spaced circular dots, arrays of chevrons and parallel arrays of dashed lines with dots could be obtained. To produce the array of dots, a tungsten wire with a diameter of $110 \mu \mathrm{m}$ was used. For the array of chevrons, copper sheets with thickness of $100 \mu \mathrm{m}$ were cut to create individual chevron-like features. The dashed lines with dots were produced using the copper sheets and the tungsten wires. After machining the tool covers, they were covered with an insulating lacquer.

Polished carbon steel workpieces were textured using various machining conditions. A combination of optimum texturing speed and accuracy was obtained for a gap between tool and specimen of $100 \mu \mathrm{m}$, voltages between 30 and $40 \mathrm{~V}, t_{p}=2.5 \mathrm{~ms}$ and $t_{o}$ $=20 \mathrm{~ms}$. Figure 4 shows an example of textured carbon steel workpieces with different patterns produced by MECT. Information about the effects of different machining parameters on texturing performance can be found in [71] and [72]. 
The removal rate in PCT obviously depends on the current density. The use of higher current densities increases the material removal rate, but it can reduce efficiency of metal dissolution. Moreover, since the tests used pulsed current, the removal rate also depends on the duty cycle, defined as the ratio $t_{o n} / t_{\text {off }}$. Typical values of machined depth / time obtained for a duty cycle of 0.15 and a current density of 0.85 A.mm ${ }^{-2}$ were around $0.5 \mu \mathrm{m} . \mathrm{s}^{-1}$.

\section{Masking by inkjet printing}

In principle, ink-jet printing can provide a method to deposit masks to be used in conjunction with etching for the texturing of engineering surfaces [101]. In early work, Muhl and Alder [102] used a continuous ink-jet printhead with a solvent-based ink to deposit mask patterns on to steel rolls; the deposited drop diameter was $\sim 150 \mu \mathrm{m}$. This process, which could readily be extended to other engineering components, was patented [103]. More recently, James [101] discussed the advantages and disadvantages of several ink types for such masking applications, and reported the printing of 120 to $150 \mu \mathrm{m}$ features on metallic substrates with a UV-cured ink. The present work used two different drop-on-demand printers for masking steel surfaces, followed by chemical etching. The first was an industrial flatbed printer (Inca Eagle) with 16 Spectra SE printheads each 128 nozzles, and UV-curable inks. The physical distance between the nozzles gives a printing resolution of 50 dpi (dots per inch) in the direction perpendicular to the printing direction. The use of more than one printhead can enhance 
the resolution. For conventional graphics printing each colour (cyan, magenta, yellow and black) can be printed using up to 4 printheads if all colours are used at once, or up to 16 printheads if monochromatic printing is used. All jets can be fired simultaneously or individually. The nozzle diameter is $38 \mu \mathrm{m}$ and the calibrated drop size is $30 \mathrm{pl}$. The second was a Dimatix Materials Printer (DMP-2800) with a nominal $10 \mathrm{pl}$ drop size. The ink was a commercial lactate solvent-based black ink (dye-based, JetStream PCS 7561 , Sun Chemical) with a viscosity of $12.1 \mathrm{mPa} \mathrm{s}$ at $25^{\circ} \mathrm{C}$ and a surface tension of $31.5 \mathrm{mN} \mathrm{m}^{-1}$.

For any printing method, to obtain reproducible printing results, it is crucial to control surface cleanliness, since a different wettability of the ink on the surface can result in printing distortions. Various cleaning routines were tried, as described in Table II. Contact angle measurements were performed for each cleaning condition using the sessile drop technique to quantify the efficiency of the cleaning methods. Additionally, a plasma chamber was also tried as a cleaning method, both for a sample that was polished 4 hours before (sample 3_F) and for a sample polished one month before (sample 3_G).

The best cleaning routine was 3_C (Figure 5), which gave the lowest contact angle and the smallest scatter between different measurements both for inks and for deionized water. Therefore, this cleaning routine was used whenever printing was not carried out immediately after polishing. 
The influence of substrate surface finish on printing and wettability was studied by comparing highly polished steel surfaces and surfaces ground with silicon carbide paper with three different grit sizes (800, 320 and 120 mesh). After grinding, the surfaces were rinsed with acetone and dried in air. Wettability for each surface condition was assessed in terms of contact angles for the solvent-based ink. The surface finishing step was performed immediately before the contact angle measurements.

Figure 6 shows that the increase of surface roughness reduced the apparent contact angle, probably due to the spreading of the ink within the surface grooves, which was observed for all the printings on roughened surfaces. According to the Wenzel's model, static contact angle measurements using a drop that is substantially larger than the roughness scale should indeed give larger values for rough surfaces when compared with a smooth surface if the solid is hydrophilic [104]. The apparent contact angle, which contains contributions both from the surface roughness and from any changes in the true, local contact angle resulting from chemical modification of the surface, controls the spreading of the ink drop. Therefore, it was concluded that roughening the surface could not be used to reduce the minimum size of the ink droplets on these metal samples.

One set of experiments using the DMP printer and solvent-based inks explored the whole texturing process, including the etching behavior and methods for stripping the resist. After printing of individual dots, the masked samples were etched with aqueous 
nitric acid at various concentrations for different periods of time. After etching, the ink deposits were stripped by immersion in acetone with ultrasonic agitation at $25{ }^{\circ} \mathrm{C}$. The samples were examined by optical microscopy before etching, after etching and after stripping. The surface topography of the textured samples was assessed by laser interferometry.

Figure 7(a) shows that the smallest features that could be printed with the DMP printer on polished steel were a pattern of circular dots (diameter $\sim 60 \mu \mathrm{m})$, where each dot was formed by a single droplet with an ejected ink drop diameter of $27 \mu \mathrm{m}$. Optimal etching behavior was found for a nitric acid concentration of 5\%. The ink protected the steel surface during etching and was easily stripped by ultrasonic cleaning in acetone. Figure 7(b) shows a 3D map of the final textured surface. The diameters of the unetched islands for an etching time of 5 minutes in $5 \%$ nitric acid were $\sim 50 \mu \mathrm{m}$, suggesting that the extent of the undercutting was $\sim 5 \mu \mathrm{m}$ per edge, and the depth was $\sim 3 \mu \mathrm{m}$ (Figure $7(\mathrm{c}))$.

However, the textures shown above are composed of a regular array of pillar-like shapes. For tribological applications in lubricated sliding, the best results have been shown for patterns composed of pocket-like or groove-like shapes. Therefore, other sets of experiments were carried out to investigate how patterns composed of regular arrays of gaps could be printed on a steel surface, with both a flatbed Eagle printer using UVcurable inks and a DMP-2800 printer using solvent-based inks. 
The tests with the flatbed printer were carried out using different numbers of printheads, printing speeds and resolutions, to identify printing routines able to produce patterns that could potentially be used in tribological applications. Some successful examples are shown in Figure 8. Parallel linear gaps of $22 \pm 5 \mu \mathrm{m}$ could be printed with 1000 dpi resolution (a). When square gaps were printed, their shape varied between adjacent rows of squares and repeated at every four rows, which is the number of printheads used to give the resolution of 1000 dpi. Interrupted lines (c) and chevron-like features ( $d$ and e) could also be produced. When printing was carried out in a single step, using four printheads simultaneously, the shape of the chevrons was more irregular (d), but the size of the chevrons was smaller than when printing was carried out in multiple steps, using one individual printhead (e).

For printing complex-shape patterns with the DMP-2800 printer using solvent-based ink, AISI 1010 steel samples were used as substrates. The minimum width that could be achieved when linear parallel gaps were printed was $20 \mu \mathrm{m}$ (Figure 9(a)). More complex shapes, such as square gaps (b) and chevrons (c) showed some distortion and the minimum size of the features was larger. Another interesting feature of printing with the solvent-based ink was that, although it was black, the thin printed films on a highly reflective steel substrate showed a clear pattern of coloured interference fringes. Surface topography measurements of the ink deposits showed that the colours could be associated with the thickness of the ink. After calibration, this provided a simple and 
reliable method to evaluate dry film thickness. This effect was not observed with the UV-curable ink (Figure 8), probably because of the reduced spreading after printing.

\section{Summary of the texturing methods}

This paper presents three alternative surface texturing methods that successfully produced texturing patterns on steel surfaces composed of: parallel grooves, regular arrays of dots (circular or square pockets), and regular arrays of chevrons, as shown schematically in Figure 10.

The methods present different characteristics, which should affect their suitability as a texturing technique for a certain tribological application. Some comparison between them is necessary to help users. The comparison criteria in this work were chosen from the database described in section 2. Since laser texturing is undoubtedly the most successful commercial texturing technique, consideration of alternative texturing techniques should include a comparison with laser texturing. However, this poses problems, since the performance of commercial laser texturing facilities can vary significantly.

If the maximum pulse energy of a laser system is higher than the ablation threshold fluence for the target material, a stationary laser beam with a spot comparable to the pocket diameter can be used to create an array of pockets without the need for laser spot scanning [28]. Small beam spot sizes result in a higher maximum energy, but require more sophisticated optics. 
Studies can be found in the literature regarding the correlation between the number of pulses and the depth of the pockets. For example, for a nanosecond (ns) laser without laser spot scanning, when the number of consecutive pulses on the same spot varied from 3 to 20, a pocket was progressively machined. This work showed that with around 10 pulses, pocket depths of around $20 \mu \mathrm{m}$ were obtained when pulse energies between 3.7 and $8.3 \mathrm{~mJ}$ during texturing of $100 \mathrm{Cr} 6$ steel samples, with small lateral damage [105]. The use of shorter pulses, besides producing small heat-affected zones, also reduces even further the time necessary to machine each pocket.

Among typical lasers, ns pulsed lasers present a good compromise between relatively short pulse duration and a reasonable cost, and hence are widely used in industrial applications [28]. However, the use of ultrashort pulses (femtosecond lasers) combined with small beam spots and high laser energy may allow higher texturing speeds.

In Table III, these methods are summarized in terms of cost and complexity, restrictions and texturing speed. For comparison, estimates are also presented for laser texturing (LT). Due to the large variability between lasers, two rough estimates are presented, one for a more standard nanosecond laser and another for a femtosecond laser with more sophisticated optics. The texturing speed was estimated as the approximate time necessary to texture a clean smooth area of $100 \times 100 \mathrm{~mm}$. Only the time necessary for masking of the surfaces (if necessary) and to machine the pockets was computed, excluding time needed for setting up the equipment or for any pre/post 
treatment. The texture pattern was composed of an array of pockets with diameter of $100 \mu \mathrm{m}$ and an area coverage of $25 \%$, which gives a total of 27889 pockets. Since the pockets are produced in a serial manner, either an $x-y$ stage moves the sample or the laser beam is steered for each pocket to be produced. Considering recent advances in commercial positioning stages and the very high speed for laser steering in modern laser facilities, it is estimated that the time to produce each pocket may vary between 1 to 10 $\mathrm{ms}$ for femtosecond laser with sophisticated optics and between 50 to $100 \mathrm{~ms}$ for standard nanosecond lasers. Therefore, the time necessary to machine 27889 pockets must be in the range from $30 \mathrm{~s}$ to $5 \mathrm{~min}$ for more sophisticated lasers and in the range from 20 to 45 minutes. It is important to emphasize that the values presented here for all the texturing techniques are only rough approximations, based on the current state of development of each technique.

The main advantage of PCT is its flexibility in terms of the shapes of the individual features. The resolution is comparable to that obtained by most commercial laser texturing facilities, although worse than the resolution of more sophisticated laser facilities. Despite the time required to mask the individual surfaces to be textured, it can be faster than laser texturing for large texturing areas, because the texturing time is independent of the area coverage.

MECT is very cheap and fast, but it can only texture surfaces with good electrical conductivity and reactivity, where a suitable anodic dissolution reaction can be 
achieved. The resolution is worse than that of laser texturing, although it is believed that the use of other techniques to produce the tool (in particular, laser machining) could help to reduce the minimum size of the features.

Masking by inkjet printing showed better resolution than MECT, but was inferior to laser texturing. Texturing results have been demonstrated for flat surfaces, but in principle the technique could also be extended to curved surfaces [47]. Despite the time necessary to mask each individual workpiece, the speed of the technique is still possibly faster than laser texturing, depending on the characteristics of the laser texturing facilities.

\section{Tribological performance}

\section{Hydrodynamic lubrication}

The summary presented in Table III shows that despite the simplifications introduced during the photolithographic masking of metal surfaces, fairly small and well-controlled features could be produced by PCT. This suggested that it could be well suited to texture sliding surfaces under hydrodynamic lubrication. To investigate this hypothesis, results from reciprocating sliding tests (stroke length $=22 \mathrm{~mm}$ and frequency $=0.55$ $\mathrm{Hz}$ ) carried out between smooth stationary cylindrical counterbodies and plane samples textured by PCT [4] are analyzed. The tests used two different counter-bodies: a mirrorpolished, $8 \mathrm{~mm}$ radius brass cylinder and a mirror-polished sector of a $100 \mathrm{~mm}$ radius aluminum alloy cylinder, both aligned perpendicularly to the sliding direction. Flooded 
lubrication conditions with a highly viscous additive-free mineral oil (dynamic viscosity of $1.5 \mathrm{~Pa} \mathrm{~s}$ at $20^{\circ} \mathrm{C}$ ), associated with a large cylinder radius, were used to ensure hydrodynamic lubrication conditions despite the non-conformal contact geometry. The geometrical characteristics of selected textured samples, measured by laser interferometry, are shown in Table IV. Table V shows the loads and the corresponding elastic contact pressures (p) and contact widths (2a) calculated from the Hertz equation for a line contact (length of the cylinder $=16 \mathrm{~mm}$ ). The texture geometries and normal loads were chosen to allow the ratio between the contact width and the size of the individual features that compose the texture pattern to be varied. No wear was detectable by optical examination of the cylinder or plane specimens after the tests, except at the ends of the strokes, suggesting that they did indeed operate with the hydrodynamic lubrication regime.

Capacitance measurements were used to evaluate film thickness, as described in [4]. After running-in, points from consecutive cycles corresponding to the same translational velocity were then averaged, to compute mean values of film thickness for an average stroke.

For the cylinder with smaller diameter and therefore narrower contact widths, the ratio between the pocket diameter and the contact width $(d / C W)$ varied between 2 and 8.5 , i.e., the pockets were substantially wider than the contact. For those cases, film thickness was reduced when compared with a smooth surface, as exemplified in Figure 
11 (a). On the other hand, for a cylinder diameter of $200 \mathrm{~mm}, d / C W$ reduced to between 0.5 and 1 , so that the pockets were normally narrower than the contact. For those cases, surface texturing could lead to increased film thickness for some texturing geometries, as exemplified in Figure 11(b), which compares film thickness as a function of the fraction of area coverage $(f)$, for samples containing circular features.

Further details of the effect of the texture geometries on film thickness and friction coefficient can be found in [4]. The results presented in this reference show that chevron-like pockets and parallel lines oriented perpendicular to the sliding direction can be particularly beneficial under certain sliding conditions, emphasizing the importance of texturing methods that are flexible in terms of the geometry of the texture patterns. However, it is important to emphasize that although the potential for texture to increase load support and reduce friction can often justify the effort and cost, in particular for hydrodynamic bearings [16], poorly chosen texture geometries or operating conditions can result in decreased load capacity.

From the alternative texturing methods presented here, PCT would be in principle the best suited for hydrodynamic applications, since it can produce the smallest features. However, it is not the absolute size of the features that is decisive in the choice of the adequate texturing method, but their relative size in relation to the operating conditions. For example, Fowell et al. [16] suggest the non-dimensional parameter $T S=a / B$, where $a$ is the distance from the inlet to the first pocket and $B$ is the pocket width, to take 
account of the width of the pocket, and the two parameters $T H=h / B$, where $h$ is the height of the pockets and $M H=h_{o} / B$, where $h_{o}=$ minimum oil film thickness, to take account of the depth of the pockets. Also, they suggest that the effect of number of pockets on the performance of a textured hydrodynamic bearing is minimal. This means that if the total area of the pockets ensures that the desired area coverage is obtained, a texturing method that generates fewer wider pockets could be adequate.

Therefore, for hydrodynamic applications where contact widths and minimum film thickness are large, such as in the case of large hydrodynamic bearings, larger pockets could be used successfully, and therefore MECT and masking by inkjet printing could also be alternatives. They would be particularly advantageous considering the size of the areas to be textured, where the texturing time could become excessively large for laser texturing.

\section{Starved lubrication}

The tribological performance of the textured surfaces was also evaluated under conditions of starved lubrication. This condition was chosen because the pockets that compose the texture are also expected to act as reservoirs for lubricant when the supply of lubricant is limited. In previous work, we have shown that this was the case for texturing dies used in strip drawing. Patterned dies showed reduced friction and resulted in better surface finish on the drawn strip when compared with smooth dies [13]. 
In the present work, the effect of surface texturing was analyzed for reciprocating sliding tests under starved liquid lubrication conditions. MECT was chosen as the texturing method because it resulted in the largest features from the three methods proposed. Flat carbon steel samples were textured with arrays of circular pockets $(d=$ $\left.190 \mu \mathrm{m}, p_{x}=320 \mu \mathrm{m}, h=10 \mu \mathrm{m}\right)$. For comparison, the smooth areas between pockets for a textured sample $\left(S_{q}=0.590 \mu \mathrm{m}\right)$ were tested under similar conditions (termed 'smooth surface'). In order to guarantee enough area between the pockets to be tested for the smooth surface, $p_{x}$ was increased to $1.4 \mathrm{~mm}$ in the comparison sample. Despite the narrow contact widths, special care was taken to position the wear track precisely over a line of pockets for the textured samples and between lines of pockets for the smooth sample.

Very small quantities of a naphthenic oil without anti-wear additives (viscosity at $40^{\circ} \mathrm{C}=0.026 \mathrm{~Pa} \mathrm{~s}$ ) were applied to the surface samples with a micropipette before reciprocating sliding tests. Different normal loads were used and therefore the ratio between the pocket diameters and the contact width $(d / C W)$ varied (Table VI).

AISI 52100 steel balls $(\phi=10 \mathrm{~mm})$ were used as counterbodies. Three repetitions were carried out for each condition. Friction force was continuously monitored with a high frequency acquisition system to allow the acquisition of many points within each stroke. To facilitate the visualization and interpretation of the data, a program developed in Matlab was used to generate a triboscopic map of the variables during the 
tests, where $z$ is friction coefficient, $x$ is the position of the counterbody within each cycle of test and $y$ is the number of the test cycle.

Figure 12 shows triboscopic maps for friction coefficients obtained for textured (left) and smooth (right) surfaces. In all maps, some peaks can be observed for the friction coefficients. This suggests that for the starved lubrication regime used in this work, the lubrication failed at some points of the surface, probably due to inability of the lubricant to refill the inlet after each pass, and that at the regions where the lubricant was present, friction coefficient was lower. For the smaller normal load of $2.5 \mathrm{~N}$, friction coefficients were high for a lubricated contact. It is believed that for such low load, the load cell used to measure friction force $($ range $=1000 \mathrm{~N})$ was not sensitive enough. However, all three tests for each sample at this load repeated the behaviours exemplified in (a) and (b). The difference between the smooth and the textured samples is not large, but for the textured samples, the friction peaks were much less frequent than for the smooth samples.

For the loads of 12.74 and $51.94 \mathrm{~N}$, the friction coefficient was larger at the ends of each stroke for all samples. Examples are shown in (c) for the textured sample and (d) for smooth samples at $51.94 \mathrm{~N}$. This might suggest that at those locations, where the speed is virtually zero, combined with the higher contact pressures and the starved lubrication conditions, lubrication failure was more significant. Also, wear debris tended to accumulate at the ends of the strokes. On the other hand, at the regions distant 
from the ends of the stroke, friction coefficient was lower for the textured sample, suggesting better lubrication. Under high normal loads, starvation is expected to be more severe. Also, the contact is wider, so that the pockets are fully contained within the contact. It is believed that under these conditions, the lubricant within the pockets is helping to replenish the contact inlet for the next cycle, reducing friction coefficient. However, despite the high acquisition rate used to sample friction force, localized friction reduction that repeated with a frequency proportional to the distance between the pockets could not be detected.

SEM of the wear tracks showed that they were wider than the diameter of the pockets for the lowest load (Figure 13), despite the pockets being wider than the elastic contact width $(d / C W=2.1)$. This might justify the occurrence of some positive effect of the texturing to replenish the contact inlet with lubricant, although it was more significant for smaller values of $d / C W$. Figure 13 (b) shows wider wear tracks at the ends of the strokes, where friction coefficients had been larger than in the middle of the strokes for the loads of 12.7 and $51.94 \mathrm{~N}$.

Those results suggest that for a texturing method to be suitable for applications involving sliding under conditions of limited supply of lubricant, it must be capable of producing features that are narrower than the sliding contact and that the effect is more significant when the ratio between the pocket diameter and the contact width is small. 
Therefore, many components that operate under limited lubricant supply could have their performance improved by any of the alternative texturing methods presented here.

Although the effect of the pocket depth was not investigated in this work, the literature $[18,22]$ suggests that when the pocket depth is very large, surface tension can drive lubricant from the contact to the bottom of the pockets, reducing the lubricant supply in the contact inlet. Such an effect was not observed in our tests, but it was reported during reciprocating sliding tests under mild starvation conditions for $d=100$ $\mu \mathrm{m}$ and $h=20 \mu \mathrm{m}$ in [18] and much more severely for $d=125 \mu \mathrm{m}$ and $h=125 \mu \mathrm{m}$ in [22].

\section{Conclusions}

This work investigated the use of alternative surface texturing methods for tribological applications.

Texturing methods were identified and classified into groups and subgroups, according to their physical principles. This included not only methods already existent either in industrial practice or research, but also new possible methods.

Three alternative texturing methods were detailed and investigated, in order to explore their viability, main characteristics, potential and limitations. All three techniques were successfully demonstrated to texture steel surfaces with patterns containing arrays of dots, lines and chevrons. 
Although photochemical texturing (PCT) is widely used in the electronics industry, the approach used in this work was much simpler and cheaper.

Maskless electrochemical texturing (MECT) is simple, cheap and fast, but the minimum size of the features is still a limitation. It involves the application of a pulsed voltage to an electrochemical cell composed of a textured tool and the workpiece.

Inkjet printing was used to mask steel surfaces, which were then etched to produce textured surfaces. The resolution was higher than for MECT, but lower than for PCT. The texturing speed depends on surface area, but it is always much slower than MECT.

A comparison of textured and smooth surfaces under hydrodynamic lubrication in reciprocating sliding showed that for the texturing method to be successful it must be able to produce pockets or grooves that are narrower than the contact width. Therefore, for components with large contacts under hydrodynamic lubrication, such as hydrodynamic bearings, any of the alternative texturing methods could be beneficial if adequate texture geometries are chosen according to the operating parameters.

A comparison of textured and smooth surfaces under starved lubrication in reciprocating sliding suggested that the pockets helped to replenish the contact with lubricant, reducing friction, in particular when the ratio between the diameter of the pockets and the contact width was low. Again, this suggests that for certain components under starved lubrication, the alternative texturing methods presented here could be 
beneficial, but this requires the choice of the texture geometry to take into account operating conditions.

\section{Acknowledgements}

The authors are grateful to Fapemig/Brazil, Capes/Brazil and the Royal Society (UK) for financial support.

\section{References}

1. Bruzzone, A.A.G., et al., Advances in engineered surfaces for functional performance. Cirp Annals-Manufacturing Technology, 2008. 57(2): p. 750-769.

2. Krupka, I., M. Vrbka, and M. Hartl, Effect of surface texturing on mixed lubricated nonconformal contacts. Tribology International, 2008. 41(11): p. 1063-1073.

3. Rapoport, L., et al., Friction and wear of MoS(2) films on laser textured steel surfaces. Surface \& Coatings Technology, 2008. 202(14): p. 3332-3340.

4. Costa, H.L. and I.M. Hutchings, Hydrodynamic lubrication of textured steel surfaces under reciprocating sliding conditions. Tribology International, 2008. 40: p. 1227-1238.

5. Etsion, I., Y. Kligerman, and G. Halperin, Analytical and experimental investigation of laser-textured mechanical seal faces. Tribology Transactions, 1999. 42(3): p. 511-516.

6. Nanbu, T., et al., Micro-textures in concentrated conformal-contact lubrication: Effects of texture bottom shape and surface relative motion. Tribology letters, 2008. 29(3): p. 241252.

7. Krupka, I. and M. Hartl, Experimental study of microtextured surfaces operating under thin-film EHD lubrication conditions. Journal of Tribology-Transactions of the Asme, 2007. 129(3): p. 502-508.

8. Etsion, I., State of the art in laser surface texturing. Journal of Tribology-Transactions of the Asme, 2005. 127(1): p. 248-253.

9. Krupka, I. and M. Hartl, The effect of surface texturing on thin EHD lubrication films. Tribology International, 2007. 40(7): p. 1100-1110.

10. Ryk, G. and I. Etsion, Testing piston rings with partial laser surface texturing for friction reduction. Wear, 2006. 261(7-8): p. 792-796.

11. Krupka, I., et al., Effect of surface texturing on elastohydrodynamically lubricated contact under transient speed conditions. Tribology International, 2011. 44(10): p. 11441150.

12. Mourier, L., et al., Lubrication mechanisms with laser-surface-textured surfaces in elastohydrodynamic regime. Proceedings of the Institution of Mechanical Engineers Part J-Journal of Engineering Tribology, 2010. 224(J8): p. 697-711.

13. Costa, H.L. and I.M. Hutchings, Effects of die surface patterning on lubrication in strip drawing. J. Mater. Process. Tech., 2009. 209(3): p. 1175-1180. 
14. Pettersson, U. and S. Jacobson, Friction and wear properties of micro textured DLC coated surfaces in boundary lubricated sliding. Tribology letters, 2004. 17(3): p. 553559.

15. Zumgahr, K.H., M. Mathieu, and B. Brylka, Friction control by surface engineering of ceramic sliding pairs in water. Wear, 2007. 263: p. 920-929.

16. Krupka, I. and M. Hartl, Effect of Surface Texturing on Very Thin Film EHD Lubricated Contacts. Tribology Transactions, 2009. 52(1): p. 21-28.

17. Ausas, R.F., M. Jai, and G.C. Buscaglia, A Mass-Conserving Algorithm for Dynamical Lubrication Problems With Cavitation. Journal of Tribology-Transactions of the Asme, 2009. 131(3).

18. Ryk, G., Y. Kligerman, and I. Etsion, Experimental investigation of laser texturing for reciprocating automotive engines. Tribology Transactions, 2002. 45(4): p. 444-449.

19. Lugt, P.M. and G.E. Morales-Espejel, A Review of Elasto-Hydrodynamic Lubrication Theory. Tribology Transactions, 2011. 54(3): p. 470-496.

20. Chiu, Y.P., Analysis and Prediction of Lubricant Film Starvation in Rolling Contact Systems. Asle Transactions, 1974. 17(1): p. 22-35.

21. Demirci, I., et al., The Scale Effect of Roughness on Hydrodynamic Contact Friction. Tribology Transactions, 2012. 55(5): p. 705-712.

22. Cho, M.H. and S. Park, Micro CNC surface texturing on polyoxymethylene (POM) and its tribological performance in lubricated sliding. Tribology International, 2011. 44(7-8): p. 859-867.

23. Shinkarenko, A., Y. Kligerman, and I. Etsion, The Effect of Elastomer Surface Texturing in Soft Elasto-Hydrodynamic Lubrication. Tribology letters, 2009. 36(2): p. 95-103.

24. Dumitru, G., et al., Laser microstructuring of steel surfaces for tribological applications. Applied Physics A, 2000. 70: p. 485-487.

25. Geiger, M., S. Roth, and W. Becker, Influence of laser-produced microstructures on the tribological behaviour of ceramics. Surf. Coat. Technol., 1998. 100-101: p. 17-22.

26. Semaltianos, N.G., et al., Femtosecond laser surface texturing of a nickel-based superalloy. Applied Surface Science, 2008. 255(5): p. 2796-2802.

27. Vincent, C., et al., Control of the quality of laser surface texturing. Microsystem Technologies-Micro-and Nanosystems-Information Storage and Processing Systems, 2008. 14(9-11): p. 1553-1557.

28. Gao, Y.B., et al., A two-step nanosecond laser surface texturing process with smooth surface finish. Applied Surface Science, 2011. 257(23): p. 9960-9967.

29. Kong, M.C., et al., On the relationship between the dynamics of the power density and workpiece surface texture in pulsed laser ablation. Cirp Annals-Manufacturing Technology, 2012. 61(1): p. 203-206.

30. Duarte, M., et al., Increasing lubricant film lifetime by grooving periodical patterns using laser interference metallurgy. Advanced Engineering Materials, 2008. 10(6): p. 554-558.

31. Kalvala, P.R., D.P. Beesabathina, and K.E. Wiedemann, Process for forming a wearresistant coating that minimizes debris, in USPTO1999, Analytical Services \& Mat. Inc.: US.

32. Deng, T., et al., Fabrication of metallic microstructures using exposed, developed silver halide-based photographic film. Analytical Chemistry, 2000. 72(4): p. 645-651.

33. Nelson, J.B. and D.T. Schwartz, Electrochemical printing: in situ characterization using an electrochemical quartz crystal microbalance. Journal of Micromechanics and Microengineering, 2005. 15(12): p. 2479-2484. 
34. Budinsky, K.G., Surface Engineering for Wear Resistance1988, New York: Prentice Hall. 44-77.

35. Xia, Y. and G.M. Whitesides, Soft lithography. Angew. Chem. Int. Ed., 1998. 37(5): p. 550-575.

36. Vaeth, K.M., et al., Use of $\mu C P$ for generating selectively grown films of poly(pphenylene vinylene) and parylenes prepared by CVD. Langmuir, 2000. 16: p. 84958500.

37. Wang, H.Y., et al., Fabrication and electron field-emission of carbon nanofibers grown on silicon nanoporous pillar array. Applied Surface Science, 2012. 261: p. 219-222.

38. Hupp, S.J. and D.P. Hart. Quantifying the effect of lubricant elasticity on microtextured surfaces. in World tribology congress III. 2005. Washington: ASME.

39. Bartz, M., et al., Stamping of monomeric SAMs as a route to structured crystallisation templates: patterned titania films. Chem. Eur. J, 2000. 6(22): p. 4149-4153.

40. Mott, M. and J.R.G. Evans, Zirconia/alumina functionally graded material made by ceramic ink jet printing. Mat Sci Eng A, 1999. 271: p. 344-352.

41. Snell, D. and A. Coombs, Novel coating technology for non-oriented electrical steels. J Magnetism and Magnetic Mat, 2000. 215-216: p. 133-135.

42. Daniel, J.H., D.F. Moore, and J.F. Walker, Focused ion beams and silicon-on-insulator a novel approach to MEMS. Smart Mater. Struct., 2000. 9: p. 284-290.

43. Hua, M., et al., Patterned PVD TiN spot coatings on M2 steel: Tribological behaviors under different sliding speeds. Wear, 2006. 260(11-12): p. 1153-1165.

44. Zou, M., L. Cai, and H. Wang, Adhesion and friction studies of a nano-textured surface produced by spin coating of colloidal silica nanoparticle solution. Tribology Letters, 2006. 21(1): p. 25-30.

45. Wuhrer, R. and W.Y. Yeung, Grain refinement with increasing magnetron discharge power in sputter deposition of nanostructured titanium aluminium nitride coatings. Scripta Materialia, 2004. 50(6): p. 813-818.

46. Lejeune, M., et al., Ink-jet printing of ceramic micro-pillar arrays. Journal of the European Ceramic Society, 2009. 29(5): p. 905-911.

47. Hutchings, I.M. and G.D. Martin, eds. Inkjet technology for digital fabrication. 2013, Wiley.

48. Pawelski, O., et al., The influence of different work-roll texturing systems on the development of surface structure in the temper rolling process of steel sheet used in the automotive industry. Journal of Materials Processing Technology, 1994. 45: p. 215-222.

49. Sheu, S. and L.G. Hector Jr., Tool surface topographies for controlling friction and wear in metal-forming processes. Transactions of ASME, Journal of Tribology, 1998. 120: $p$. 517-527.

50. Mailis, S., et al., Etching and printing of diffractive optical microstructures by a femtosecond excimer laser. Applied Optics, 1999. 38(11): p. 2303-2308.

51. Wakuda, M., et al., Effect of surface texturing on friction reduction between ceramic and steel materials under lubricated sliding contact. Wear, 2003. 254(3-4): p. 356-363.

52. Fu, Y.H., et al., The technology of laser honing applied in distinctively improving the Iubrication of frictional units. Key Engineering Materials, 2001. 202-203: p. 265-270.

53. Aspinwall, D.K., et al., Electrical Discharge Texturing. J. Mach. Tools Manufact., 1992. 32(12): p. 183-193.

54. De Soete, D., D. Pans, and K. Steinhoff, EBT technology and its applications. Iron and Steel Engineering, 1997(September): p. 36-40. 
55. Langford, R.M., et al., Focused ion beam micromachining of three-dimensional structures and three-dimensional reconstruction to assess their shape. J. Micromech. Microeng, 2002. 12: p. 111-114.

56. Chae, Y.H., Effect of size for micro-scale dimples on surface under lubricated sliding contact, in Mechanical Behavior of Materials X, Pts 1and 2, S.W. Nam, et al., Editors. 2007, Trans Tech Publications Ltd: Stafa-Zurich. p. 765-768.

57. Zhang, J.Y. and Y.G. Meng, A study of surface texturing of carbon steel by photochemical machining. Journal of Materials Processing Technology, 2012. 212(10): p. 2133-2140.

58. Leyendecker, R. and G. Heinke, Method and apparatus for reducing fretting wear between relatively moving parts, in USPTO1976, Robert Bosch G.m.b.H: United States.

59. Schonenberger, I. and S. Roy, Microscale pattern transfer without photolithography of substrates. Electrochimica Acta, 2005. 51(5): p. 809-819.

60. Shinkarenko, A., Y. Kligerman, and I. Etsion, The Validity of Linear Elasticity in Analyzing Surface Texturing Effect for Elastohydrodynamic Lubrication. Journal of Tribology-Transactions of the Asme, 2009. 131(2).

61. Bowden, N., et al., Self-assembly of mesoscale objects into ordered two-dimensional arrays. Science, 1997. 276(11 Apr): p. 232-235.

62. Ishibashi, K., Methods for treating the surface of a solid body, in USPTO1993: US.

63. Srinivasarao, M., et al., Three-dimensionally ordered array of air bubbles in a polymer film. Science, 2001. 292(6 April): p. 79-83.

64. Melcher, R.L., L.T. Romankiw, and R.J. Von Gutfeld, Method for maskless chemical machining, in USPTO1983, IBM: US.

65. Tian, H., N. Saka, and N.P. Suh, Boundary lubrication studies on undulated titanium surfaces. Tribology Transactions, 1989. 32(3): p. 289-296.

66. Li, L. and D.M. Chai, The research and application of honing technology. Key Engineering Materials, 2001. 202-203: p. 385-388.

67. Nguyen, T.A. and D.L. Butler, Simulation of precision grinding process, part 1: generation of the grinding wheel surface. International Journal of Machine Tools \& Manufacture, 2005. 45(11): p. 1321-1328.

68. Tian, H. and A.M. Chao, Optimization of disk surface texturing and lubrication on CSS performance. IEEE Trans. Magnet., 1996. 32(5): p. 3666-3668.

69. Gordon, N., D. Starosvetsky, and Y. Ein-Eli, Negative potential dissolution (NPD)advanced and rapid texturing method of as-cut silicon. Electrochimica Acta, 2005. 50(27): p. 5313-5321.

70. Cooper, C.V., P. Holiday, and A. Matthews, The effect of tin interlayers on the indentation behavior of diamond-like carbon-films on alloy and compound substrates. Surface \& Coatings Technology, 1994. 63(3): p. 129-134.

71. Costa, H.L. and I.M. Hutchings, Development of a Maskless Electrochemical Texturing Method. Journal of Materials Processing Technology, 2009. 209(8): p. 3869-3878.

72. Zhu, D., et al., Model-based virtual surface texturing for concentrated conformal-contact lubrication. Proceedings of the Institution of Mechanical Engineers Part J-Journal of Engineering Tribology, 2010. 224(J8): p. 685-696.

73. Slikkerveer, P.J. and F.H. Veld, Model for patterned erosion. Wear, 1999. 233-235: p. 377-386.

74. Mastud, S., et al., Experimental Characterization of Vibration-Assisted Reverse Micro Electrical Discharge Machining (EDM) For Surface Texturing. Proceedings of the Asme International Manufacturing Science and Engineering Conference, 20122012. 439-448. 
75. Byun, J.W., et al., Surface Texturing by Micro ECM for Friction Reduction. International Journal of Precision Engineering and Manufacturing, 2010. 11(5): p. 747-753.

76. Stutzmann, N., et al., Patterning of polymer-supported metal films by microcutting. Nature, 2000. 407(5 October): p. 613-616.

77. Heuberger, M., et al., Dynamic control of friction via surface structuring, in Boundary and Mixed Lubrication: Science and Applications, D. Dowson, Editor 2002, Elsevier. p. 67-73.

78. Bulatov, V.P., V.A. Krasny, and Y.G. Schneider, Basics of machining methods to yield wear- and fretting-resistive surfaces, having regular roughness patterns. Wear, 1997. 208: p. 132-137.

79. dos Santos, D.S., et al., The role of azopolymer/dendrimer layer-by-layer film architecture in photoinduced birefringence and the formation of surface-relief gratings. Langmuir, 2006. 22(14): p. 6177-6180.

80. Okamoto, T., et al., Ultraviolet-cured polymer microlens arrays. Applied Optics, 1999. 38(14): p. 2991-2996.

81. De Mello, J.D.B., J.L. Goncalves, Jr., and H.L. Costa, Influence of surface texturing and hard chromium coating on the wear of steels used in cold rolling mill rolls. Wear, 2013. 302(1-2): p. 1295-1309.

82. Steinhoff, K., A. Kapoor, and N. Guillon, Controlled wear as mechanism for the design of geometrically defined nanometric surface structures on forming tools. Advanced Technology of Plasticity, 1999. 1: p. 265- 270.

83. Fletcher, D.I., et al., Wear behaviour and surface form evaluation of a novel titanium carbide implanted surface under lubricated conditions. Proc. Inst. Mech. Engrs., 2000. 214(J): p. 597-610.

84. Costa, H.L., et al. Alternative methods for surface texturing. in 1st International Brazilian Conference on Tribology. 2010. Rio de Janeiro, Brazil: ABM.

85. Gutierrez-Mora, F., et al., Dry and oil-lubricated sliding wear of Si3N4 and Si3N4/BN fibrous monoliths. Tribology Letters, 2005. 18(2): p. 231-237.

86. McGillis, D.A., Lithography, in VLSI Technology, S.M. Sze, Editor 1983, McGrawHill. p. 267-302.

87. Pardo, D.A., Application of screen printing in the fabrication of organic light-emitting devices. Advanced Materials, 2000. 12(7): p. 1249-1252.

88. Vicenzi, D., Low power thick-film gas sensor obtained by a combination of screenprinting and micromachining techniques. Thin Solid Films, 2001. 391: p. 288-292.

89. Leppavuori, S., et al., A novel thick-film technique, gravure offset printing, for the realization of fine-line sensor structures. Sensors and Actuators A, 1994. 41-42: p. 593596.

90. Michel, B., et al., Printing meets lithography: soft approaches to high-resolution patterning. IBM J. Res. \& Dev., 2001. 45(3): p. 697-719.

91. Darhuber, A.A. and S. Wagner, Physical mechanisms governing pattern fidelity in microscale offset printing. Journal of Applied Physics, 2001. 90(7): p. 3602-3609.

92. Rampelbe, V.H., Hot-stamping becomes economical for large areas. Modern Plastics, 1970. 47(9): p. 112-114.

93. Kumar, A.V. and A. Dutta, Electrophotographic layered manufacturing. Journal of Manufacturing Science and Engineering, 2004. 126(August): p. 571-576.

94. Carlson, C.F. and J. Heights, Electrophotography, in USPTO1942.

95. Castrejon-Pita, J.R., et al., Future, opportunities and challenges of inkjet technologies. Atomization and Sprays, 2013. 23(6): p. 541-565. 
96. Costa, H.L., Modification of surface topography: manufacturing methods and applications, in Engineering Department2005, University of Cambridge: Cambridge. p. 240.

97. Marian, V.G., et al., Theoretical and Experimental Analysis of a Laser Textured Thrust Bearing. Tribology letters, 2011. 44(3): p. 335-343.

98. Madou, M.J., Fundamentals of Microfabrication. 2nd ed. The Science of Miniaturization2002, Florida: CRC Press. 723.

99. Vishnitsky, A., Electrochemical rifling of gun barrels, in USPTO1987, Cation Corporation: United States.

100. Parreira, J.G., C.A. Gallo, and H.L. Costa, New Advances on Maskless Electrochemical Texturing (MECT) for Tribological Purposes. Surf. Coat. Tech., 2012. 212: p. 1-13.

101. James, M. Photochemical Machining by Ink Jet. A Revolution in the Making? in NIP20: International Conference on Digital Printing Technologies. 2004. Salt Lake City: IS\&T.

102. Muhl, J. and G.M. Alder, Direct Printing of Etch Masks under Computer Control. International Journal of Machine Tools \& Manufacture, 1995. 35(2): p. 333-337.

103. Muhl, J., Surface treatment of an object, in WIPO1995: International Bureau.

104. Gennes, P.-G.d., F. Brochard-Wyart, and D. Quere, Wetting of textured surfaces, in Capillarity and Wetting Phenomena: Drops, Bubbles, Pearls, Waves2003, Springer. p. 216-226.

105. Vilhena, L.M., et al., Surface texturing by pulsed Nd:YAG laser. Tribology International, 2009. 42(10): p. 1496-1504.

106. Costa, H.L. and I.M. Hutchings. Ink-jet printing for patterning engineering surfaces. in NIP24/Digital fabrication 2008: 24th International conference on digital printing technologies. 2008. Pittsburgh, PA. 


\section{List of figures}

Figure 1. Schematic representation of the tree structures for methods involving: (a) removing material; (b) adding material; (c) moving material; (d) self-forming by wear.

Figure 2. Schematics of the tree structure for methods for mask generation.

Figure 3. Examples of the surface topography texture patterns generated by photochemical texturing using: (a and b) positive photoresist, circular pockets; and (c and d) negative photoresist, circular pillars; images on left show 3D maps and on right show line profiles.

Figure 4. Examples of a steel sample textured by MECT, adapted from [100], with permission: (a) 3D map of a regular array of pockets; (b) profile across a line of circular pockets; (c) 3D map of a regular array of chevrons; (d) profile across the vertices of the chevrons.

Figure 5. Contact angle measurements for different cleaning routines, average of five measurements, for magenta and black inks and water.

Figure 6. Contact angle measurements on steel samples with different surface roughness; larger grit sizes give smoother surfaces.

Figure 7. Printing of individual dots, DMP-2800 printer (adapted from [106]): (a) optical microscopy after printing; (b) 3D map after etching and stripping; (c) line profile. 
Figure 8. Examples of complex shapes printed with a flatbed eagle printer and UVcurable ink: (a) parallel linear gaps; (b) rectangular gaps; (c) interrupted linear gaps; (d) chevrons, single-step printing using four printheads; (e) chevrons, multiple-step printing using one individual printhead.

Figure 9. Examples of complex printings using DMP-2800 printer, solvent-base ink; adapted from [106], with permission: (a) $20 \mu \mathrm{m}$ gap between parallel printed lines; (b) $40 \mu \mathrm{m}$ square gap; (c) chevrons.

Figure 10. Geometrical definitions of the textured patterns.

Figure 11. Comparison (average strokes) between film thickness for smooth and textured samples: (a) $16 \mathrm{~mm}$ brass cylinder, normal load $=2.5 \mathrm{~N}$, samples T16 (circles) and T17 (lines); (b) $200 \mathrm{~mm}$ aluminium cylinder, load $=51.5 \mathrm{~N}$, circles, effect of area coverage $(f)$, adapted from [4], with permission.

Figure 12. Triboscopic maps for textured (left) and smooth (right) surfaces: (a) 2.94 $\mathrm{N}$, textured; (b) $2.94 \mathrm{~N}$, smooth; (c) $51.94 \mathrm{~N}$, smooth; (d) $51.94 \mathrm{~N}$, smooth, adapted from [100], with permission.

Figure 13. SEM Of the wear tracks, BSE: (a) textured sample, 2.94N; (b) smooth sample, $12.7 \mathrm{~N}$. 


\section{List of tables}

Table I. Experimental conditions for the photolithographic procedure.

Table II. Cleaning routines before inkjet printing; USC = ultrasonic cleaning; $\mathrm{HAB}=$ hot air blower; IMS = industrial methylated spirit.

Table III. Summary of the alternative texturing methods; the geometrical dimensions of the features are defined in Figure 10.

Table IV. Dimensions (in $\mu \mathrm{m}$ ) of the features in the texture patterns; NA $=$ not applicable; the nomenclature for the dimensions is described in Figure 10.

Table V. Normal loads and corresponding contact pressures and elastic contact widths, calculated from Hertz equation.

Table VI. Normal loads with respective Hertz calculations. 


\section{Removing material}

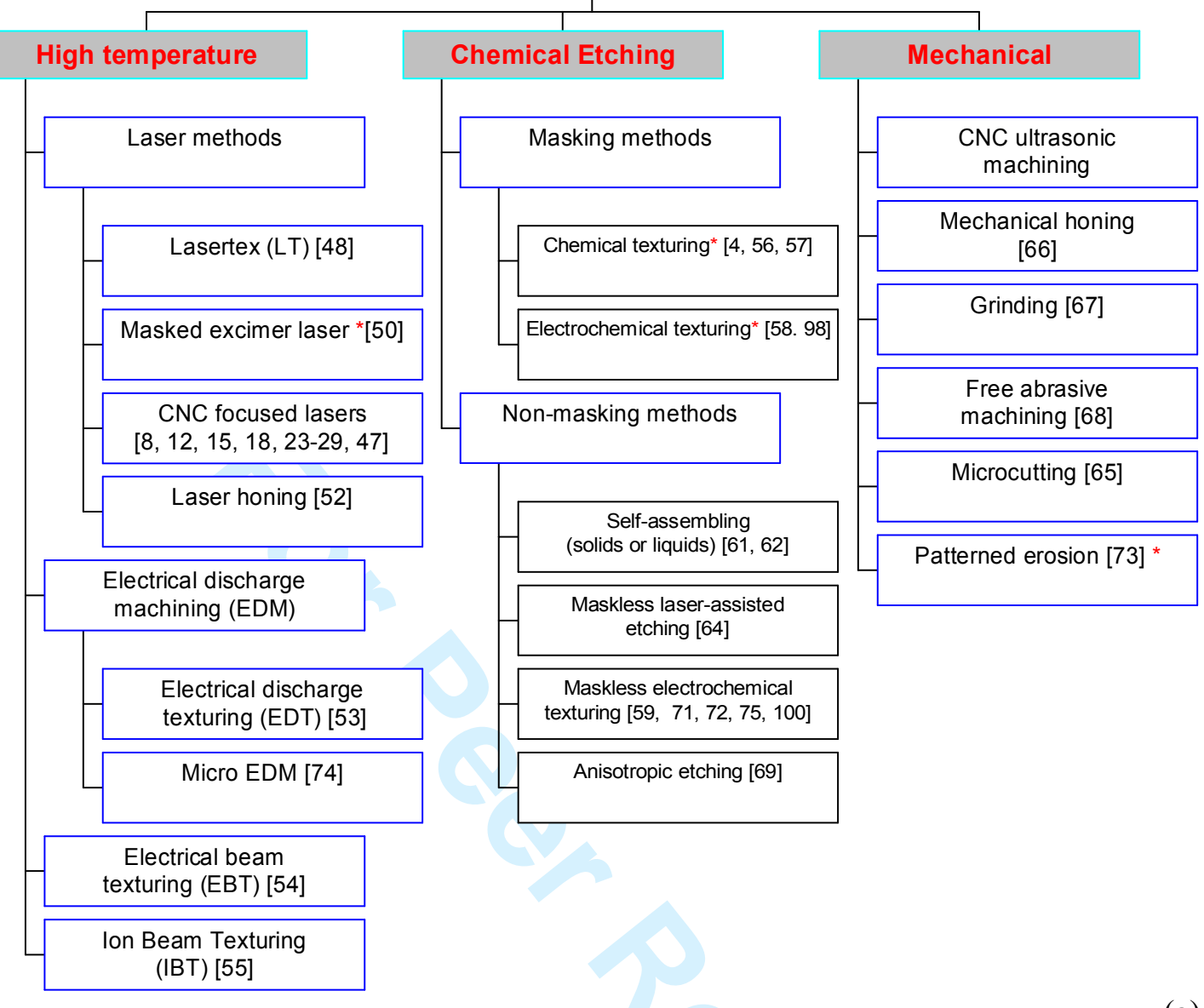

Fig. 1 


\section{Physical Deposition}

Inkjet for deposition of wear-resistant patterns $[40,46,47]$

FIB for deposition of wear-resistant patterns [42]

Patterned curing [41]

Patterned deposition of organic coatings (painting) [86-95]

Electrochemical printing [33]

Spin coating of micro and nano particles [44]

(b)

Fig. 1 
Fig. 1 
2

Fig. 1 


\section{Page 49 of 85}

1

2

3

4

5

6

7

8

9

10

11

12

13

14

15

16

17

18

19

20

21

22

23

24

25

26

27

28

29

30

31

32

33

34

35

36

37

38

39

40

41

42

43

44

45

46

47

48

49

50

51

52

53

54

55

56

57

58

59

60

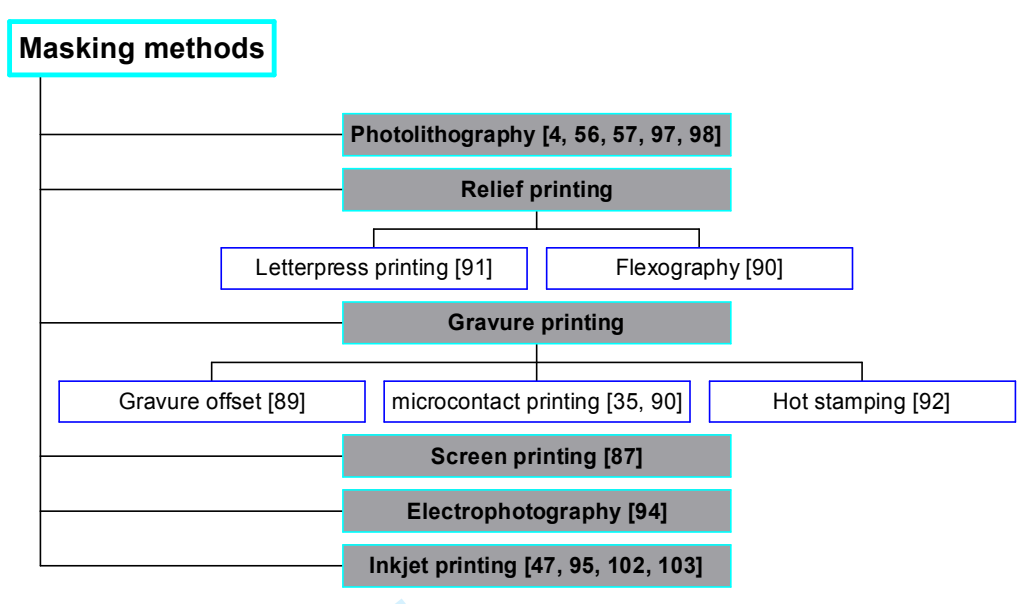

Fig. 2

.

http://mc.manuscriptcentral.com/(site) 


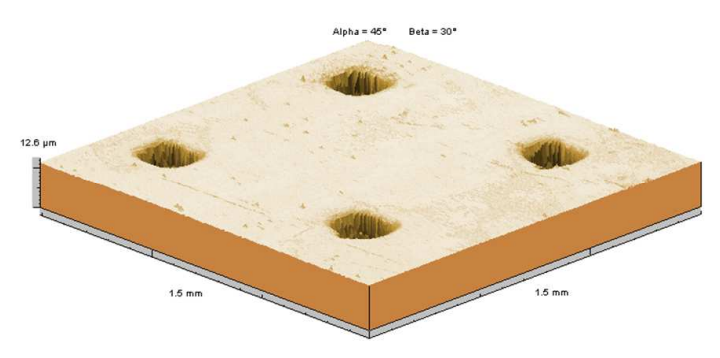

(a)

Figure 3

http://mc.manuscriptcentral.com/(site) 


\section{Page 51 of 85}

Journal name

1

2

3

4

5

6

7

8

9

10

11

12

13

14

15

16

17

18

19

20

21

22

23

24

25

26

27

28

29

30

31

32

33

34

35

36

37

38

39

40

41

42

43

44

45

46

47

48

49

50

51

52

53

54

55

56

57

58

59

60

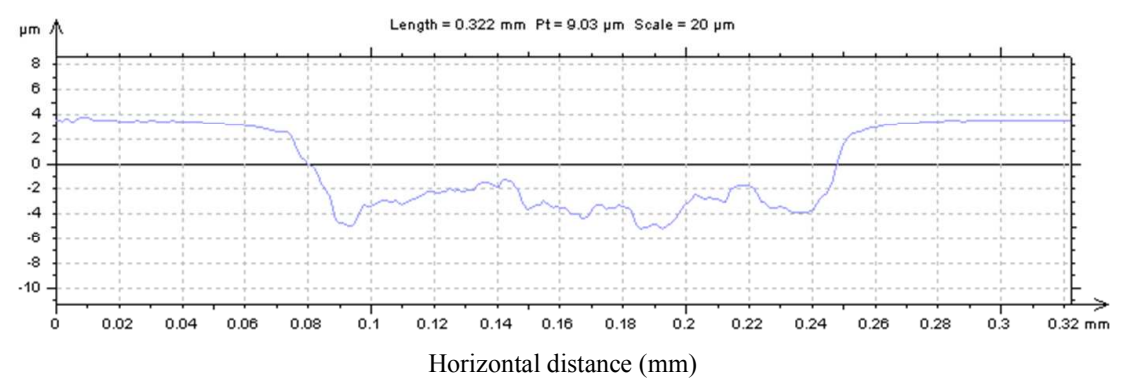

(b)

Figure 3 


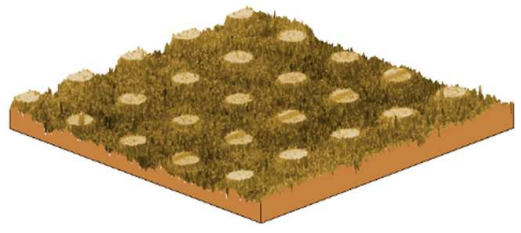

(c)

Figure 3 


\section{Page 53 of 85}

Journal name

1

2

3

4

5

6

7

8

9

10

11

12

13

14

15

16

17

18

19

20

21

22

23

24

25

26

27

28

29

30

31

32

33

34

35

36

37

38

39

40

41

42

43

44

45

46

47

48

49

50

51

52

53

54

55

56

57

58

59

60

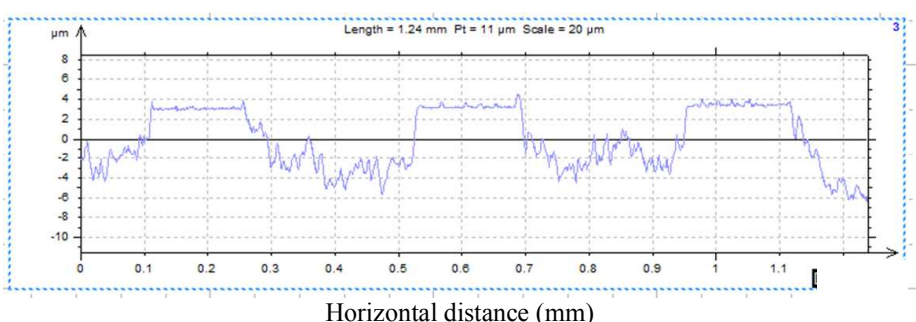

(d) 


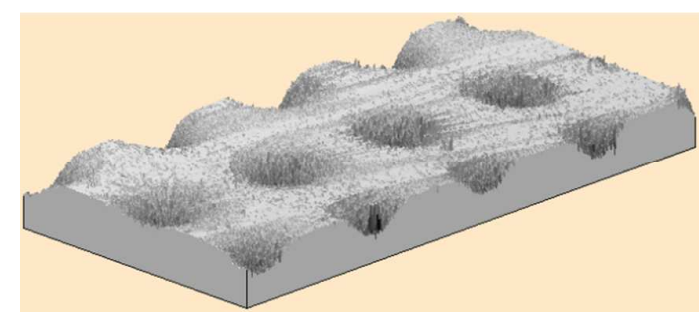

(a)

Figure 4 


\section{Page 55 of 85}

Journal name

1

2

3

4

5

6

7

8

9

10

11

12

13

14

15

16

17

18

19

20

21

22

23

24

25

26

27

28

29

30

31

32

33

34

35

36

37

38

39

40

41

42

43

44

45

46

47

48

49

50

51

52

53

54

55

56

57

58

59

60

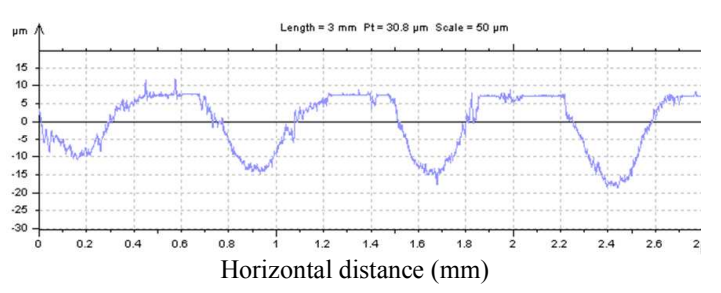

(b)

Figure 4

http://mc.manuscriptcentral.com/(site) 
Journal name

Page 56 of 85

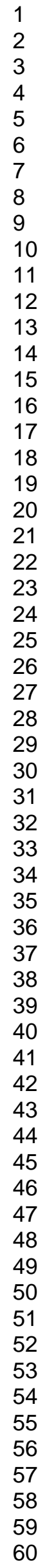

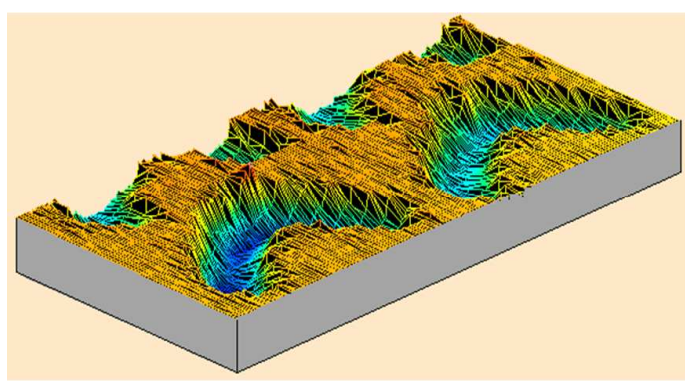

(c)

Figure 4

http://mc.manuscriptcentral.com/(site) 
1

2

3

4

5

6

7

8

9

10

11

12

13

14

15

16

17

18

19

20

21

22

23

24

25

26

27

28

29

30

31

32

33

34

35

36

37

38

39

40

41

42

43

44

45

46

47

48

49

50

51

52

53

54

55

56

57

58

59

60

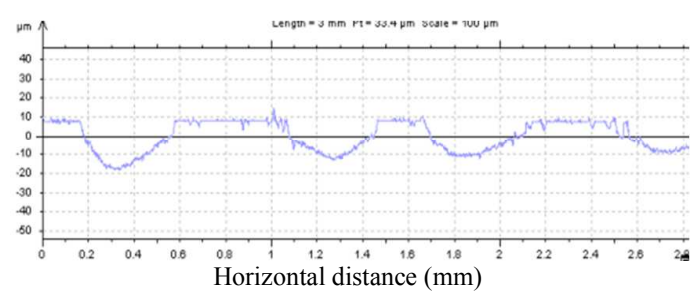

(d)

Figure 4

http://mc.manuscriptcentral.com/(site) 


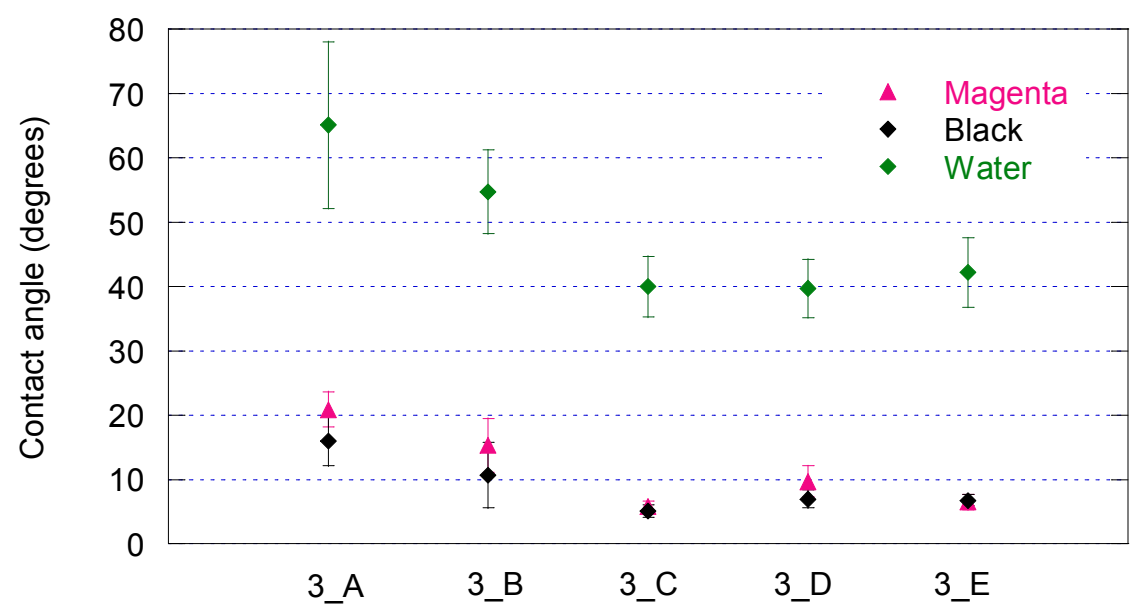

Figure 5

http://mc.manuscriptcentral.com/(site) 


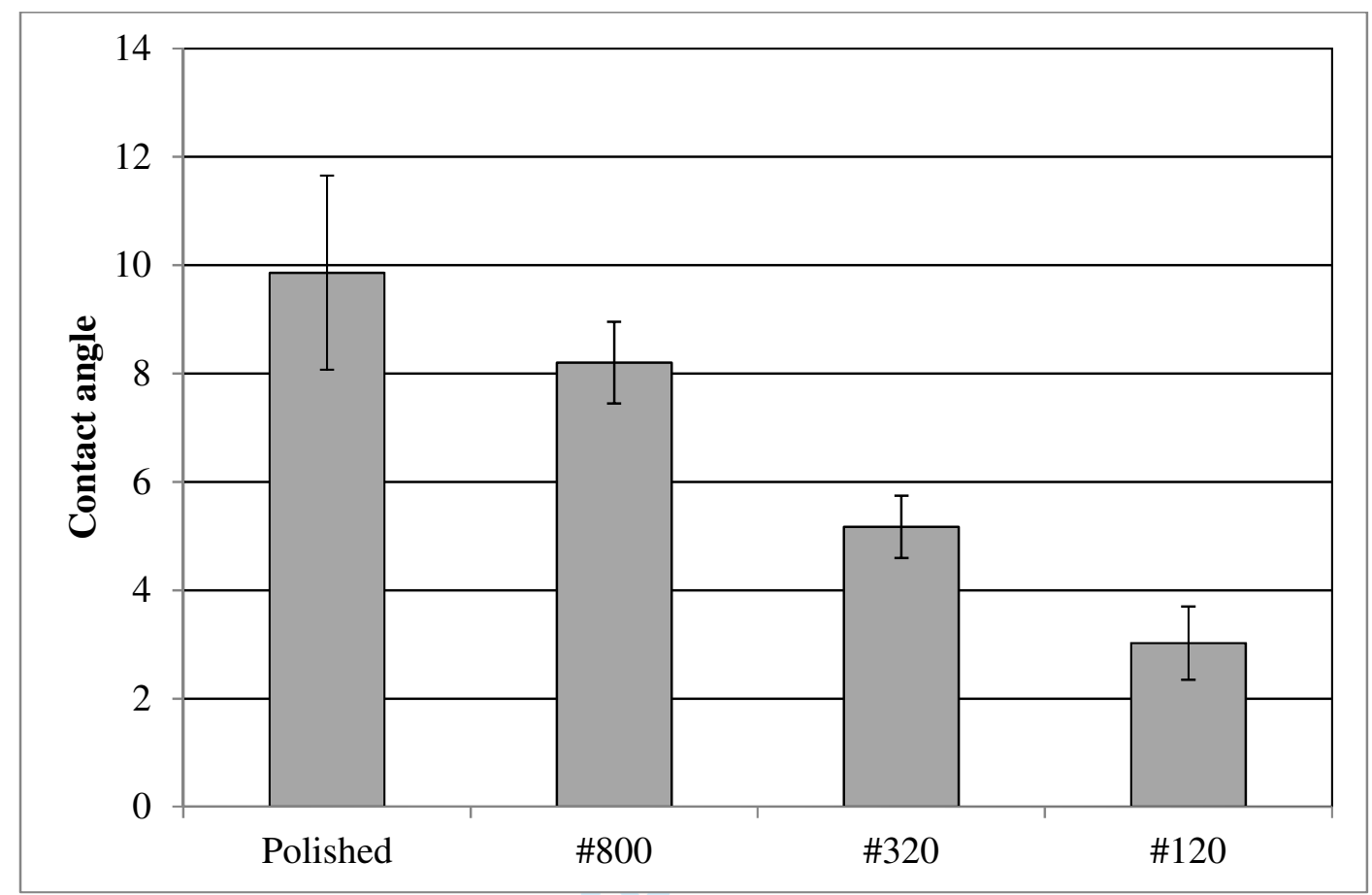

Figure 6

http://mc.manuscriptcentral.com/(site) 


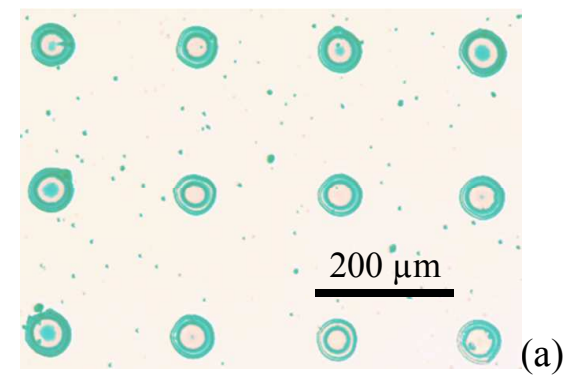

Figure 7

http://mc.manuscriptcentral.com/(site) 


\section{Page 61 of 85}

1
2
3
4
5
6
7
8
9

2

3

4

5

6
7

8

10

11

12

13

14

15

16

17

18

19

20

21

22

23

24

25

26

27

28

29

30

31

32

33

34

35

36

37

38

39

40

41

42

43

44

45

46

47

48

49

50

51

52

53

54

55

56

57

58

59

60

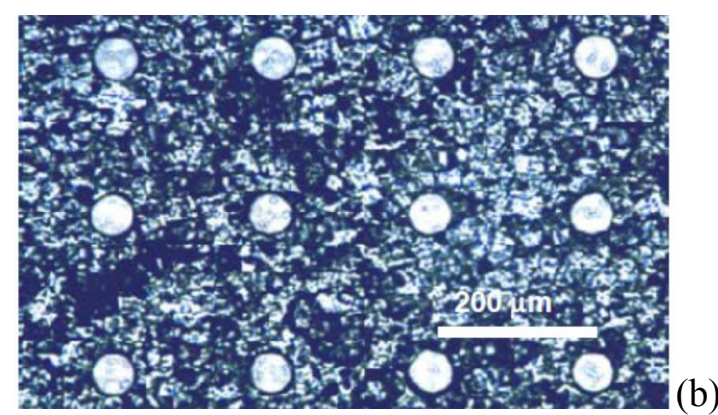

Figure 7

(b)

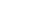




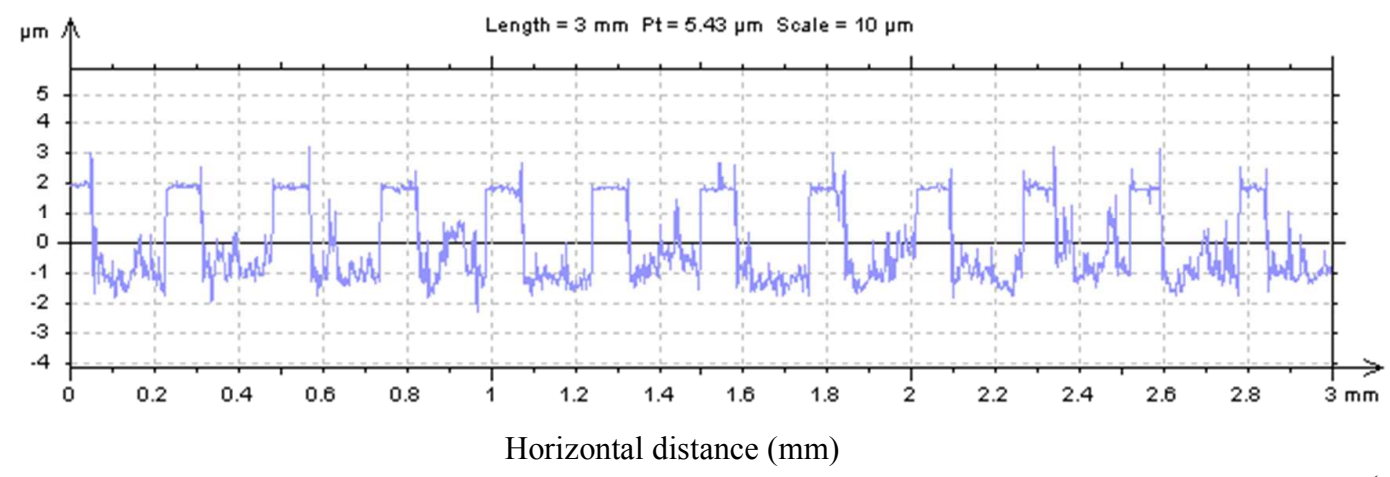

(c)

Figure 7

http://mc.manuscriptcentral.com/(site) 


\section{Page 63 of 85}

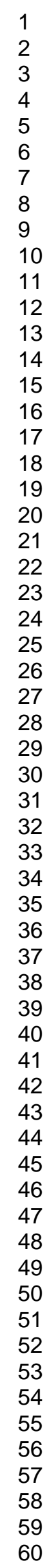

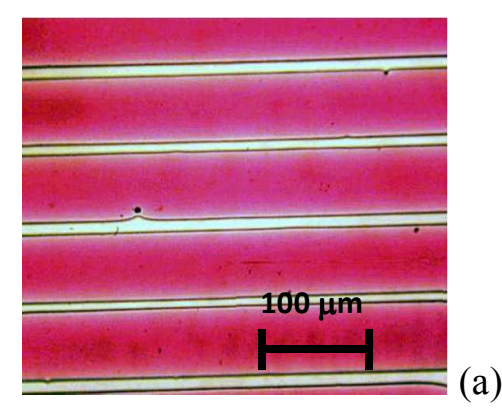

Figure 8

http://mc.manuscriptcentral.com/(site) 


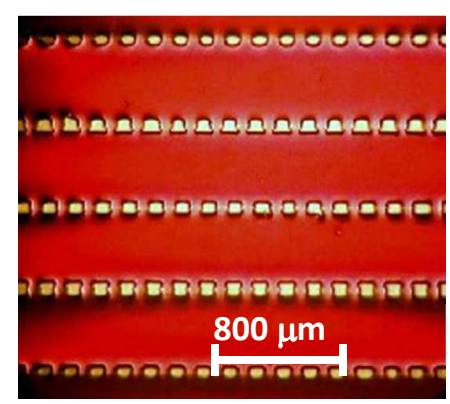

(b)

Figure 8

16

18

19

20

21

22

23

24

25

26

27

28

29

30

31

32

33

34

35

36

37

38

39

40

41

42

43

44

45

46

47

48

49

50

51

52

53

54

55

56

57

58

59

60

http://mc.manuscriptcentral.com/(site) 


\section{Page 65 of 85}

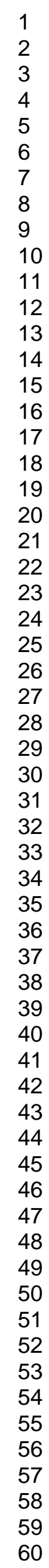

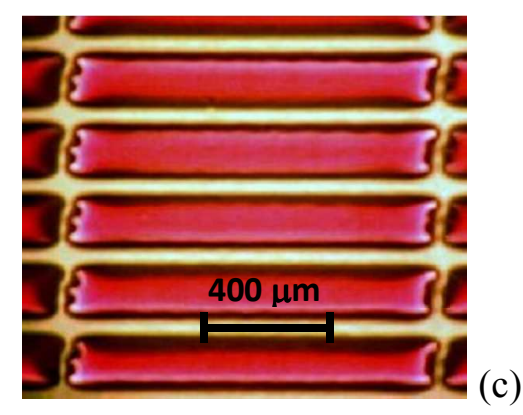

Figure 8

http://mc.manuscriptcentral.com/(site) 


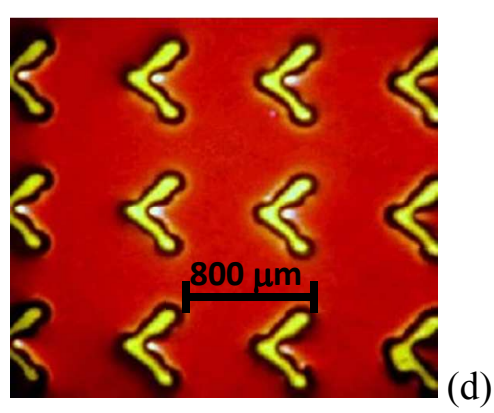

Figure 8

17

18

19

20

21

22

23

24

25

26

27

28

29

30

31

32

33

34

35

36

37

38

39

40

41

42

43

44

45

46

47

48

49

50

51

52

53

54

55

56

57

58

59

60

http://mc.manuscriptcentral.com/(site) 


\section{Page 67 of 85}

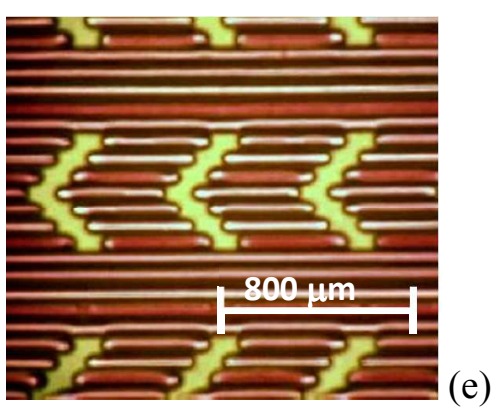

Figure 8

(e)

14

15

16

17

18

19

20

21

22

23

24

25

26

27

28

29

30

31

32

33

34

35

36

37

38

39

40

41

42

43

44

45

46

47

48

49

50

51

52

53

54

55

56

57

58

59

60

http://mc.manuscriptcentral.com/(site) 


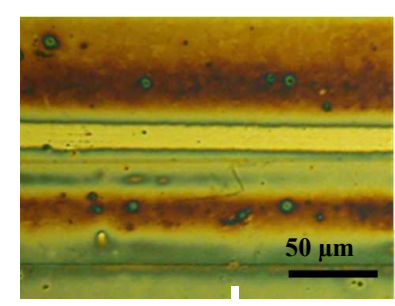

(a)

Figure 9

14

15

16

17

18

19

20

21

22

23

24

25

26

27

28

29

30

31

32

33

34

35

36

37

38

39

40

41

42

43

44

45

46

47

48

49

50

51

52

53

54

55

56

57

58

59

60

http://mc.manuscriptcentral.com/(site) 


\section{Page 69 of 85}

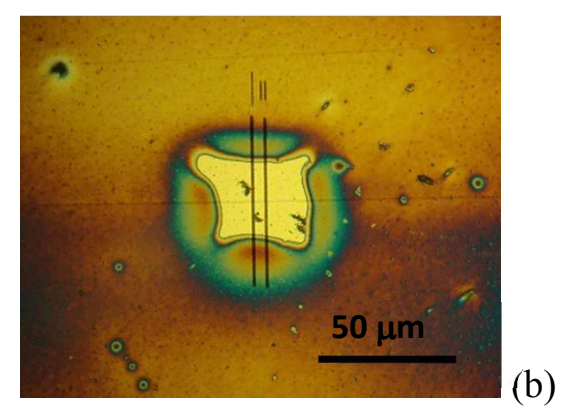

Figure 9

1
2
3
4
5
6
7
8
9
10

17

18

19

20

21

22

23

24

25

26

27

28

29

30

31

32

33

34

35

36

37

38

39

40

41

42

43

44

45

46

47

48

49

50

51

52

53

54

55

56

57

58

59

60

http://mc.manuscriptcentral.com/(site) 


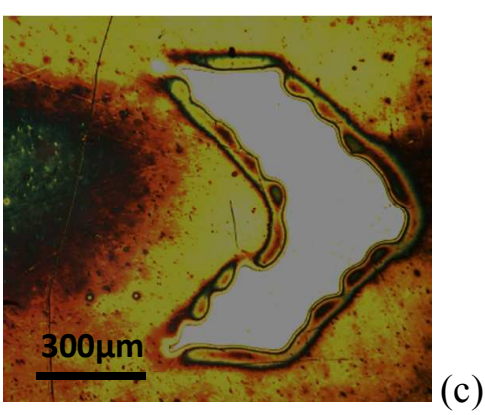

Figure 9

18

19

20

21

22

23

24

25

26

27

28

29

30

31

32

33

34

35

36

37

38

39

40

41

42

43

44

45

46

47

48

49

50

51

52

53

54

55

56

57

58

59

60

http://mc.manuscriptcentral.com/(site) 
1

2

3

4

5

6

7

8

9

10

11

12

13

14

15

16

17

18

19

20

21

22

23

24

25

26

27

28

29

30

31

32

33

34

35

36

37

38

39

40

41

42

43

44

45

46

47

48

49

50

51

52

53

54

55

56

57

58

59

60

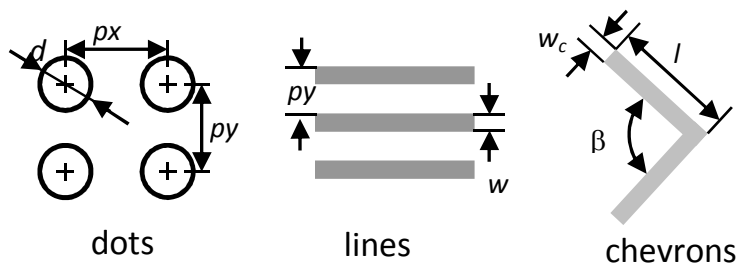

Figure 10

http://mc.manuscriptcentral.com/(site) 


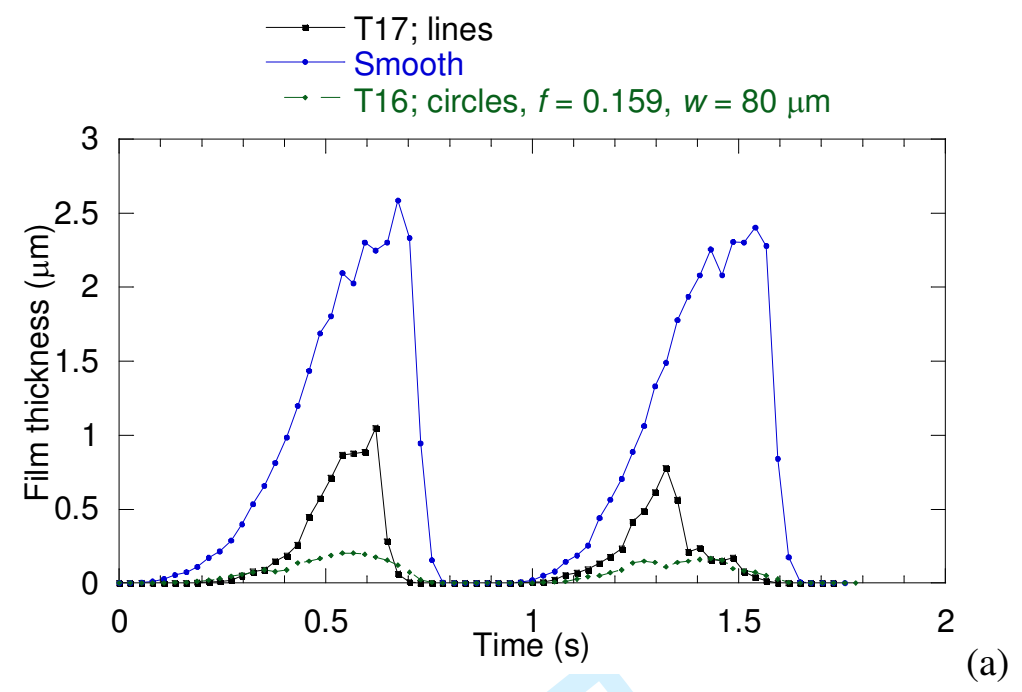

Figure 11

http://mc.manuscriptcentral.com/(site) 


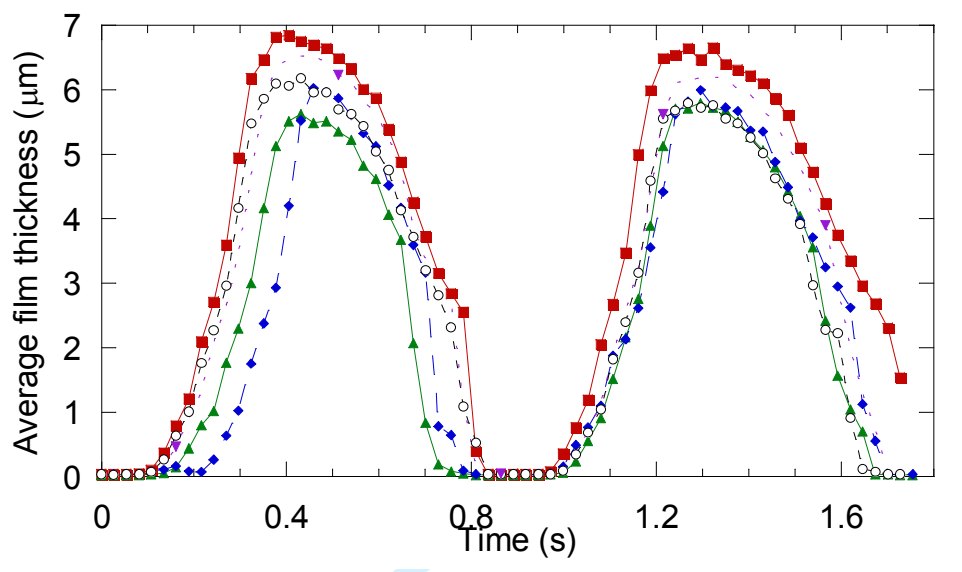

(b)

Figure 11 


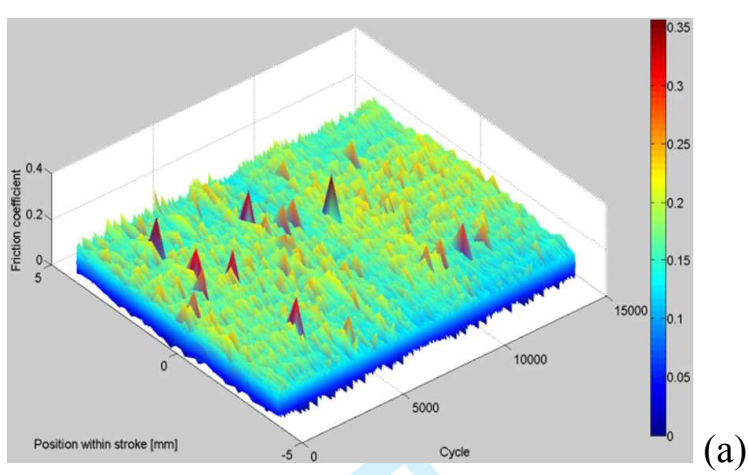

Figure 12

http://mc.manuscriptcentral.com/(site) 


\section{Page 75 of 85}

Journal name

1
2
3
4
5
6
7
8
9
10
11
12
13
14
15
16
17
18
19
20
21
22
23
24
25
26
27
28
29
30
31
32
33
34
35
36
37
38
39
40
41
42
43
44
45
46
47
48
49
50
51
52
53
54
55
56
57
58
60

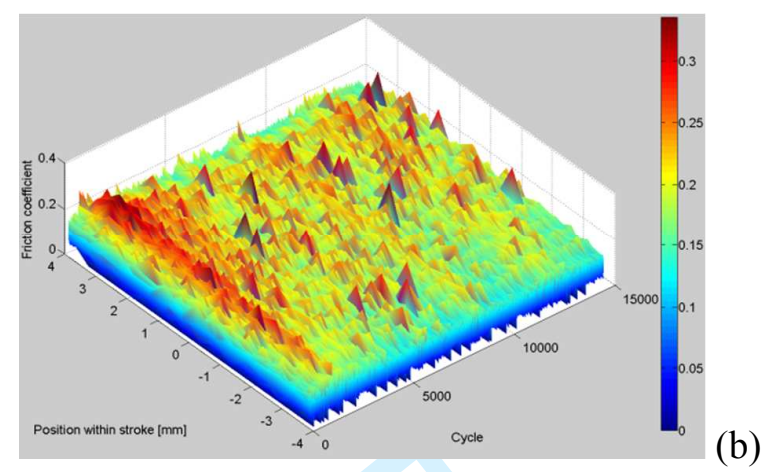

Figure 12

http://mc.manuscriptcentral.com/(site) 


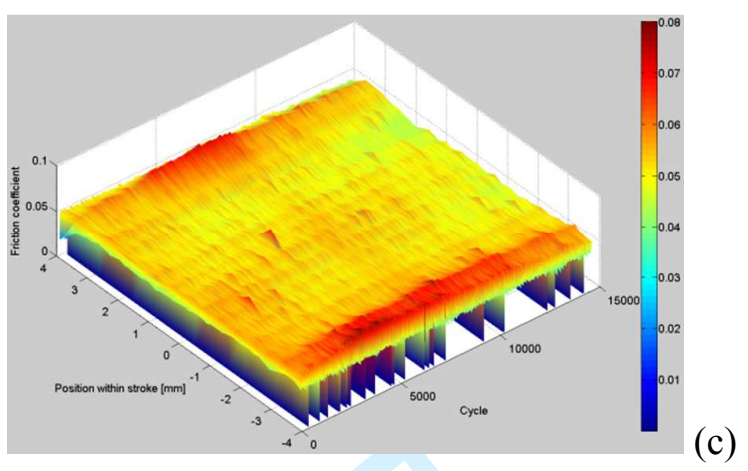

Figure 12

http://mc.manuscriptcentral.com/(site) 


\section{Page 77 of 85}

Journal name

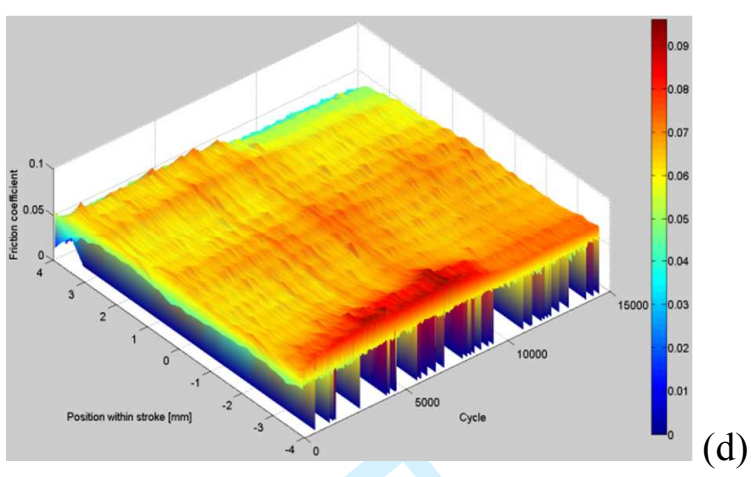

Figure 12

3

4

5

7

8

9

10

11

12

13

16

17

18

19

20

21

22

23

24

25

26

27

28

29

30

31

32

33

34

35

36

37

38

39

40

41

42

43

44

45

46

47

48

49

50

51

52

53

54

55

56

57

58

59

60

http://mc.manuscriptcentral.com/(site) 


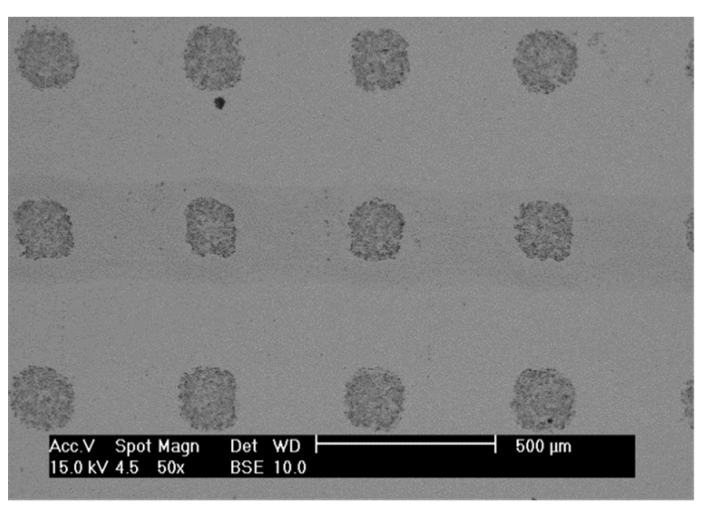

(a)

Figure 13

http://mc.manuscriptcentral.com/(site) 


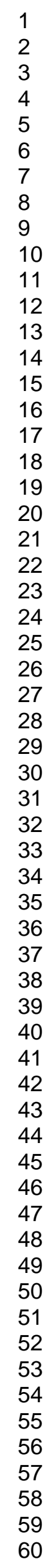

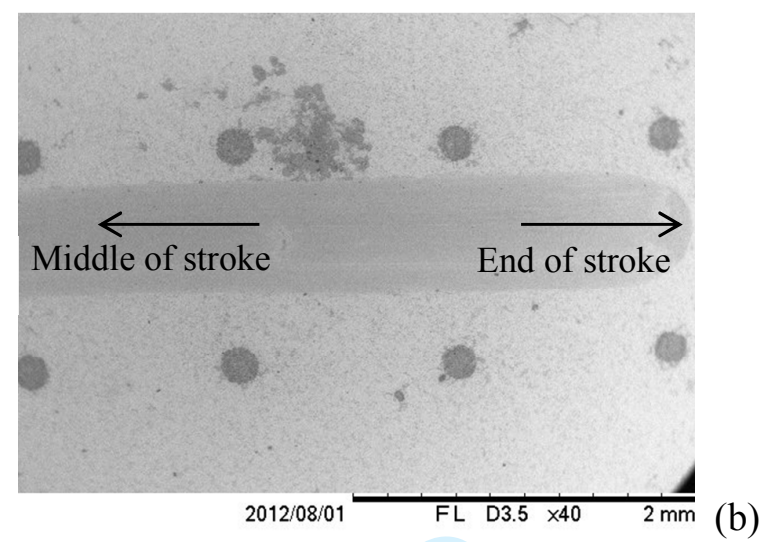

Figure 13

http://mc.manuscriptcentral.com/(site) 
Table I

\begin{tabular}{ccc}
\hline Conditions & Negative resist & Positive resist \\
\hline Sppining rotation $(\mathrm{rpm})$ & 3000 & 4000 \\
Spinning time $(\mathrm{s})$ & 60 & 30 \\
Pre-baking temperature $\left({ }^{\circ} \mathrm{C}\right)$ & 95 & 95 \\
Pre-baking time $(\mathrm{s})$ & 60 & 60 \\
Exposure time $(\mathrm{s})$ & 300 & 300 \\
Developing time $(\mathrm{s})$ & 180 & $30-60$ \\
Post-baking temperature $\left({ }^{\circ} \mathrm{C}\right)$ & 150 & 150 \\
Post-baking time $(\mathrm{s})$ & 180 & 180 \\
\hline
\end{tabular}

http://mc.manuscriptcentral.com/(site) 
Table II

\begin{tabular}{|c|c|}
\hline Sample & SURFACE CONDITIONS \\
\hline $3 \_\mathrm{A}$ & Polished ( $1 \mu \mathrm{m}$ diamond) one month before and cleaned with acetone \\
\hline 3 & d ( $1 \mu \mathrm{m}$ diamond) up to $4 \mathrm{~h}$ before and cleaned with acetone \\
\hline 3 & $\begin{array}{l}\text { Condition } 3 \text { B, cleaned for } 5 \text { min. in } 36 \% \text { wt } \mathrm{NaCO}_{3} \text { using USC, rinsed, sprayed with } \\
\text { IMS and dried with HAB }\end{array}$ \\
\hline 3_D & $\begin{array}{l}\text { Condition } 3 \text { B } \text {, cleaned for } 5 \text { min. in } 36 \% \text { wt } \mathrm{NaCO}_{3} \text { using USC, rinsed, cleaned for } 5 \\
\text { min. in detergent }+ \text { warm water, rinsed, sprayed with IMS and dried with } \mathrm{HAB}\end{array}$ \\
\hline 3_E & $\begin{array}{l}\text { Condition } 3 \text { A, cleaned cleaned for } 5 \text { min. in } 36 \% \text { wt } \mathrm{NaCO}_{3} \text { using USC, rinsed, } \\
\text { sprayed with IMS and dried with HAB }\end{array}$ \\
\hline
\end{tabular}

http://mc.manuscriptcentral.com/(site) 
Table III

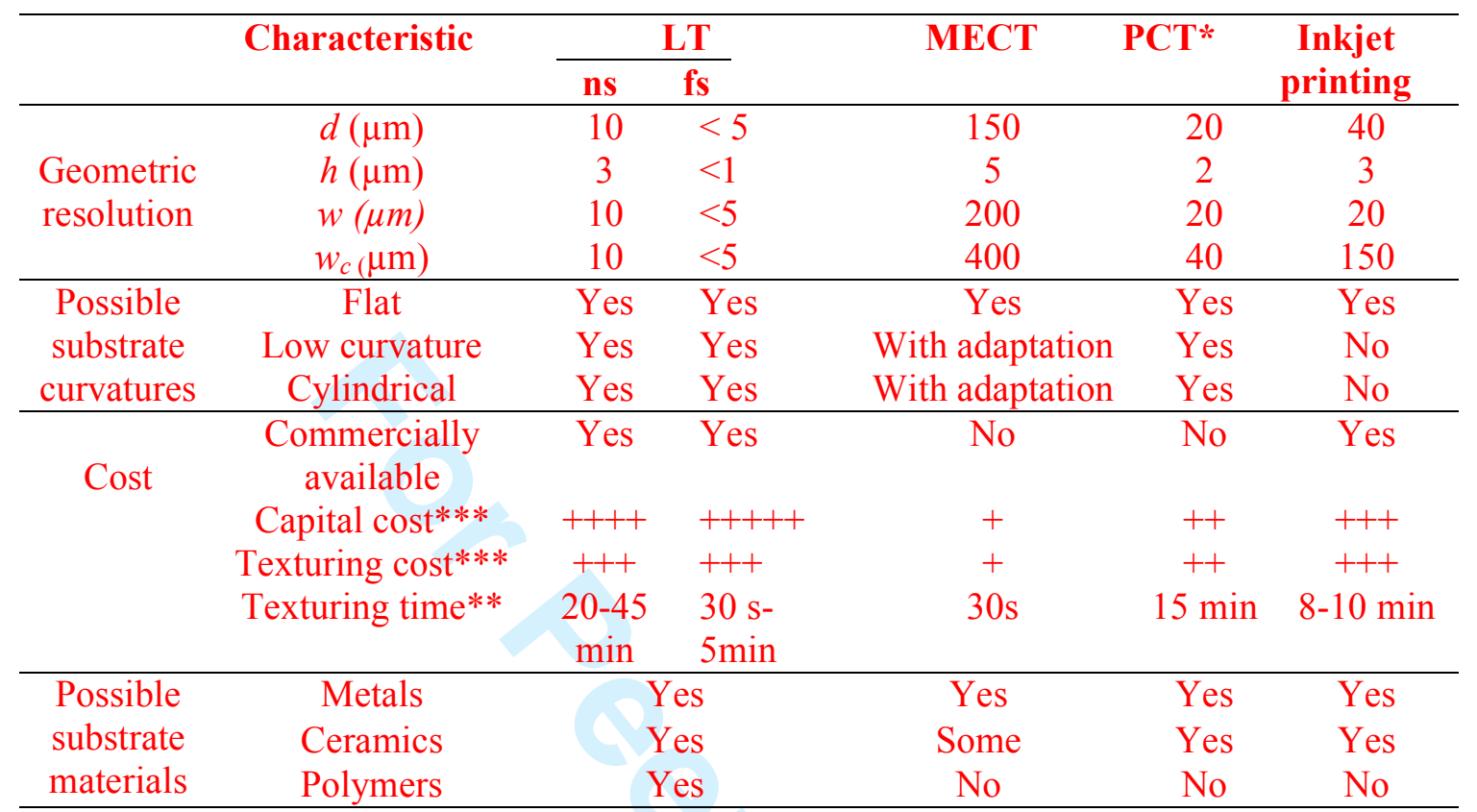

*the characteristics presented are based on the simplified version presented in this paper and not using conventional photolithography.

**approximate time for texturing a smooth clean area of $100 \times 100 \mathrm{~mm}, d=150 \mu \mathrm{m}, h=$ $20 \mu \mathrm{m}, f=0.15$, no pre or post-treatment included.

*** "+" means very low and " +++++ " means high. 
Table IV

\begin{tabular}{lccccccc}
\hline Pattern & Sample & $\boldsymbol{h}$ & $\boldsymbol{d}$ & $\boldsymbol{P x}$ or Py & $\boldsymbol{w}$ & $\boldsymbol{\beta}$ & $\boldsymbol{l}$ \\
\hline \multirow{4}{*}{ Circles } & $\mathrm{T} 1$ & 4.5 & 41 & & NA & NA & NA \\
& $\mathrm{T} 2$ & 4.5 & 40 & & NA & NA & NA \\
& $\mathrm{T} 3$ & 4.5 & 47 & & NA & NA & NA \\
& T4 & 6 & 70 & & NA & NA & NA \\
& T16 & 2 & 80 & 56 & NA & NA & NA \\
\hline Lines & T17 & 4.5 & NA & 52 & 42 & NA & NA \\
\hline Chevrons & T10 & 4.5 & NA & NA & 132 & 70 & 190 \\
\hline
\end{tabular}

http://mc.manuscriptcentral.com/(site) 
Table V

\begin{tabular}{|c|c|c|c|c|}
\hline \multirow{2}{*}{$\begin{array}{c}\text { Load } \\
(\mathbf{N})\end{array}$} & \multicolumn{2}{|c|}{$16 \mathrm{~mm}$ brass cylinder } & \multicolumn{2}{|c|}{$200 \mathrm{~mm}$ aluminum cylinder } \\
\hline & $\begin{array}{l}\text { Contact width } \\
(\mu \mathrm{m})\end{array}$ & $\begin{array}{c}\text { Contact pressure } \\
(\mathrm{MPa})\end{array}$ & $\begin{array}{c}\text { Contact width } \\
(\mu \mathrm{m})\end{array}$ & $\begin{array}{c}\text { Contact } \\
\text { pressure (Mra) }\end{array}$ \\
\hline 2.5 & 9.2 & 472 & \multicolumn{2}{|c|}{ Not used } \\
\hline 12.3 & 21 & 2320 & 82 & 146 \\
\hline 22.1 & \multirow{7}{*}{\multicolumn{2}{|c|}{ Not used }} & 111 & 262 \\
\hline 31.9 & & & 133 & 379 \\
\hline 41.7 & & & 152 & 496 \\
\hline 51.5 & & & 169 & 612 \\
\hline 61.3 & & & 184 & 729 \\
\hline 71.1 & & & 198 & 845 \\
\hline 80.9 & & & 212 & 962 \\
\hline
\end{tabular}

http://mc.manuscriptcentral.com/(site) 
6

7

8

9

Table VI

\begin{tabular}{cccc}
\hline Normal load (N) & Maximum contact pressure (MPa) & Contact width CW $(\boldsymbol{\mu m})$ & $\boldsymbol{d} \mathbf{C W}$ \\
\hline 2.94 & 631 & 94.4 & 2.1 \\
12.74 & 1029 & 153.8 & 1.2 \\
51.94 & 1643 & 245.7 & 0.8 \\
\hline
\end{tabular}

20

21

22

23

24

25

26

27

28

29

30

31

32

33

34

35

36

37

38

39

40

41

42

43

44

45

46

47

48

49

50

51

52

53

54

55

56

57

58

59

60

http://mc.manuscriptcentral.com/(site) 